\title{
Forecasting concentrations of organic chemicals in the vadose zone caused by spills of hydraulic fracturing wastewater
}

\author{
Lanting $\mathrm{Ma}^{\mathrm{a}}$, Antonio Hurtado ${ }^{\mathrm{b}}$, Sonsoles Eguilior ${ }^{\mathrm{b}, *}$, Juan F. Llamas Borrajo ${ }^{\mathrm{a}}$ \\ a Escuela Técnica Superior de Ingenieros de Minas y Energía de Madrid, Calle de Ríos Rosas 21, 28003 Madrid, Spain \\ b Centro de Investigaciones Energéticas, Medioambientales y Tecnológicas, Avda. Complutense 40, Edif. 20, 28040 Madrid, Spain
}

\section{H I G H L I G H T S}

- Forecast for the temporary evolutions of concentrations and volumes of the pollutant source

- Predictive evolution of VOC concentrations in soil/air/aquifer

- Dynamic behaviour associated with scenarios of natural conditions

- The model can be a tool to improve the monitoring strategy.

\section{GRAPH ICALA B S T R A C T}

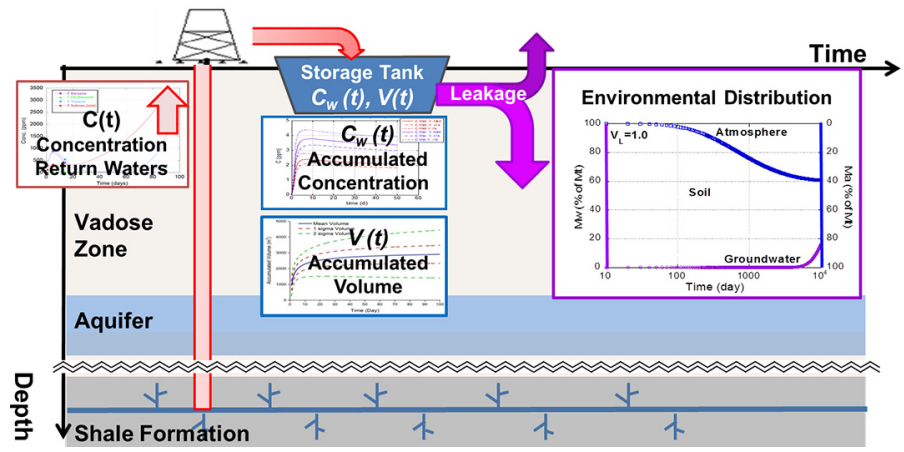

\begin{abstract}
A B S T R A C T
The return water from hydraulic fracturing operations is characterised by high concentrations of salts and toxic organic compounds. This water is stored on the surface in storage tanks and/or ponds. Wastewater spills caused by inappropriate storage can lead to the contamination of various environmental compartments, thus posing a risk to human health. Such risk can be determined by estimating the concentrations of the substances in the storage system and the behaviour of the same in function of the characteristics of the environment in which they are released.

To this end, here we addressed the evolution of the concentrations of pollutants in a tank used to store wastewater from hydraulic fracturing operations. To do this, we estimated both the volume of flowback and the concentrations of the pollutants found in these waters. We then examined the dynamic behaviour of spill-derived compounds in the various environmental compartments in function of the conditions of the medium (humid, semiarid, and arid). This approach allowed us to rank the hazard posed by the chemical compounds in question, as well as to determine those parameters associated with both the compounds and external natural conditions that contribute to environmental risk. Our results shed greater light on the mechanism by which external environmental variables (especially recharge rate) influence the migration of organic compounds in the vadose zone, and contribute to the prediction of their concentrations. Also, by estimating the time that chemicals remain in contaminated areas, we identify the phases of contamination that pose the greatest risk to human health. In summary, the approach used herein allows the ranking of compounds on the basis of risk to human health and can thus facilitate the design of pollutant management strategies. Of note, our ranked list highlights the relevance of benzene.
\end{abstract}

(C) 2019 Elsevier B.V. All rights reserved.

\footnotetext{
* Corresponding author.

E-mail address: sonsoles.eguilior@ciemat.es (S. Eguilior).
} 


\section{Introduction}

The extraction of unconventional fossil fuels on a commercial scale in several regions of the world has increased dramatically over the last 15 years [IEA, 2017]. In this regard, this practice is focused mainly in the USA, which has increased its shale gas production to 630 billion $\mathrm{m}^{3}$. Greater exploitation of these fuels can be explained by various factors, including an estimated 30\% increase in the global demand for energy between now and 2040 [IEA, 2017], directives to reduce carbon dioxide emissions, and technological advances in horizontal drilling and hydraulic fracturing. Despite a recent slowdown of activity, energy development is likely continue, with shale gas and tight oil production estimated to grow 60\% by 2040 compared to 2015 production [Patterson et al., 2017]. This rapid increase in unconventional oil and gas production has undoubtedly brought numerous benefits to society. However, this development has also generated considerable controversy due to environmental safety issues, such as dewatering streams, and surface and groundwater pollution [Patterson et al., 2017]. In this new context, the determination of the impact of unconventional oil and gas exploitation is now a scientific priority when formulating energy policies and risk management practices. In this regard, experience gained in unconventional fossil fuel extraction, particularly in the USA, can facilitate prediction of the effects of this practice on the environment and human health [Werner et al., 2015]. Such prediction also provides the opportunity to anticipate the measures required to minimize harmful effects. Furthermore, risk prediction is particularly relevant given that there is currently no EU framework directive on the regulation of such exploitation activities.

The exploitation of unconventional oil and gas resources often implies a large number of wells, which generate a significant volume of wastewater. For instance, in North Dakota, approximately 9700 unconventional wells have an estimated production of 31.4·109 gal (118,900 million L) of oil and gas wastewater, based on an average production of over 1 million barrels of oil per day in the Bakken region [Lauer et al., 2016].

In the context of unconventional gas extraction, a fracturing fluid (usually water with various additives) is injected into the reservoir at very high pressure to expand fractures and increase the porosity and permeability of the rock. Throughout the USA, shale gas extraction has resulted in the use of 116 billion L of fluid annually from 2012 to 2014.

The gas or oil extraction process brings the return water, which is subdivided into flowback and produced water, to the surface, and yielded similar volumes to those of the used water [Kondash and Vengosh, 2015; Kondash et al., 2018; Luek and Gonsior, 2017].

The composition of this water is highly variable since it contains a complex mixture of fluids of different nature, ranging from the injected fluids themselves to compounds extracted from the shale formation, including salts, metals, radionuclides, oil and gas compounds, and natural organic matter [Luek and Gonsior, 2017; Akob et al., 2015].

In exploitations of shale gas in the USA, return water is usually stored in lined ponds or tanks. The former are rarely free from flaws and leakage can be expected over time. Similarly, the permeability of clay-lined ponds can be increased by the salinity of the water stored [Council of Canadian Academies, 2014]. In this regard, the groundwater near the Marcellus shale gas operations in north-eastern Pennsylvania has been reported to be contaminated by diesel-range organic compounds via the accidental release of chemicals derived from above-ground hydraulic fracturing activities [Drollette et al., 2015]. In addition, leakages from storage and disposal pits around the Pavillion field in Wyoming are responsible for the high concentrations of benzene, xylenes, gasolinerange organic compounds, and diesel-range hydrocarbons found in shallow ground [DiGiulio et al., 2011]. Inorganic contamination associated with brine spills has also been reported in North Dakota [Lauer et al., 2016]. Remarkably, the contamination this region is significantly persistent, with elevated concentrations of contaminants observed in spill sites up to 4 years after the spill events.

Studies conducted on surface spill incident databases provide useful information about the number of wells involved, the volume of return waters discharged into the environment, and the probability of such events [Abualfaraj et al., 2018]. According to studies conducted by the USA Environmental Protection Agency (EPA), in which data from state agencies, oil and gas production well operators and hydraulic fracturing service companies were assessed, 457 hydraulic fracturing-related spills occurred between January 2006 and April 2012 [USA EPA, 2015]. More recent studies considering spills from unconventional oil and gas wells in Colorado, New Mexico, North Dakota and Pennsylvania from 2005 to 2014 revealed that between $2 \%$ and $16 \%$ of the wells reported a spill each year [Patterson et al., 2017; Clancy et al., 2018]. While the largest spills exceeded $100 \mathrm{~m}^{3}$, median spill volumes ranged from $0.5 \mathrm{~m}^{3}$ in Pennsylvania to $4.9 \mathrm{~m}^{3}$ in New Mexico. Seventy-five to $94 \%$ of spills occurred within the first three years of well-life after drilling, completion and recording their largest production volumes. Across all four states, $50 \%$ of spills were related to storage and the transport of fluids via flow lines [Patterson et al., 2017]. These data reflect that thousands of cubic meters of wastewater derived from hydraulic fracturing operations have been accidentally released into the environment in various spill scenarios both in the USA and Canada.

Thus, given the volume of return water generated and its composition, one of the greatest environmental risks associated with shale gas extraction operations is the potential of this wastewaters to pollute surface water and shallow groundwater through spills, leaks, and/or the disposal of inadequately treated shale gas wastewater [Vengosh et al. 2014a and 2014b; Gross et al., 2013], and the resulting long-term effect on human populations and aquatic ecosystems [He et al., 2018]. We focused our study on organic compounds because of their high toxicity and thus potential risk to human health and the environment. Quantification of these pollution would facilitate the identification of the measures that should be taken by industry and improve the regulations that govern both the location of ponds used to store return water and groundwater monitoring near them [Council of Canadian Academies, 2014].

To this end, it is necessary to determine the concentrations of pollutants in tanks used to store return water derived from hydraulic fracturing operations and to study the primary characteristics associated with the behaviour of these pollutants and their mobility in various types of soils. To predict the behaviour of these substances upon leakage, we used a dynamic transport model of organic chemicals in subsurface media. Given the large number of substances that can be found in the return waters, as well as the lack of available data, this study required the following: (1) grouping of organic compounds by family on the basis of similar behaviour and toxicity; (2) selection of organic compounds for inclusion in this study, on the basis of their concentrations and negative impact; (3) estimation of their maximum concentration in the surface storage tank; and (4) study of their migration in the gas and dissolved liquid phases. This approach allowed the modelling of results of cumulative mass percentage curves in the various contamination phases and total concentration curves under the different recharge rate conditions to obtain and to quantify pollutant release in a groundwater table to a finite depth as a function of time. These are key elements for prediction purposes and therefore essential from a risk management perspective [Jury et al., 1990; Shan and Stephens, 1995]. In this regard, knowledge of the distribution of the expected volumes of the organic compounds during environmental contamination and their expected concentrations both in the storage tanks and soil would facilitate the design of specific remediation strategies adapted to the behaviours observed [Drollette et al., 2015; Elliott et al., 2016; He et al., 2017; Council of Canadian Academies, 2014].

\section{Methods and materials}

\subsection{Chemical concentration in the storage tank}

To assess the potential environmental and health risks associated with the leakage of on-site pit storage water onto the surface, a 
phenomenon reported to have the largest potential impact on the surrounding environment [Kuwayama et al., 2015; Krupnick et al., 2013], it is essential to determine the concentration of pollutants in these wastewaters.

In this regard, the volume of return waters, as well as the potential of chemical compounds to be transported to the surface by these waters, is unpredictable. However, information from existing exploitations can serve as guides. Here we estimated the expected concentrations of pollutants in the storage tank on the basis of: the forecasting volume of return water, calculated using the values coming from an experimental database [Hayes, 2009] adjusting according an empirical expression [Ma, 2018]; and the contaminant concentration in this water, calculated by a predictive model which assess their evolution that has been adjusted from experimental data [Ma et al., 2018]. This information is very useful in the first management phases of the return waters, and will serve as a basis for further design of safety plans that include the monitoring and development of mitigation measures.

Specifically, we used data released by the Marcellus Shale Coalition (Hayes database) in a report of the Gas Technology Institute from 19 Marcellus wells located in three sites in the northern half of West Virginia and 16 wells in Pennsylvania, all of which were exploited by hydraulic fracturing [Hayes, 2009]. We took into account the concentration of organic compounds from all horizontal wells (Locations C, D, E, F, G, K, M and $\mathrm{O}$ in the Hayes report).

Analysis of the return water revealed the presence of more than 212 organic compounds. In addition, approximately $96 \%$ of volatile organic compounds (VOCs) in flowback water were found at nondetectable levels; among semi VOCs (SVOCs), more than $98 \%$ of all determinations were at non-detectable levels (Hayes, 2009). Given the difficulty of an individualized treatment because of the above reasons, we grouped the organic compounds based on their relationships of similarity in the evolution over time of their concentrations in the return water [Ma et al., 2018] and their physico-chemical (mainly $k_{o c}$ - soil organic carbon-water partitioning coefficientand solubility) and eco-toxicological properties. Finally, we used the following eight categories: acetophenone; benzene; phenol; TEX; TMB (1,2,4-trimethylbenzene, 1,3,5-trimethylbenzene); RBenzene (isopropylbenzene, N-butylbenzene, N-propylbenzene, Sec-butylbenzene, P-isopropyltoluene); NAPH (naphthalene); and PAHs-NAPH.

\subsubsection{Concentration of organic compounds in return water}

The concentrations of the contaminants present in return waters can be described with the Two-compartment First-order Rate Constant (TFRC) kinetic model developed in [Ma et al., 2018]. This empirical model (Eq. (1)) is based on the observation of biphasic desorption and the shape of desorption profiles [Ma et al., 2018].

$$
\begin{aligned}
C_{f}^{\alpha}(t)= & \frac{C_{0}}{2} \cdot \operatorname{erfc}\left[\frac{x-\left(v / R_{d}\right) \cdot t}{2 \sqrt{\left(D / R_{d}\right)} \cdot t}\right] \\
& \cdot\left[\exp \left(-k_{\text {fast }} \cdot t\right)+\phi \cdot \exp \left(-k_{\text {slow }} \cdot t\right)\right]
\end{aligned}
$$

where $C_{f}^{\alpha}(t)$ is the concentration of contaminant at time $t$ in the flowback or produced water [Mass $\cdot$ Length $^{-3}$ ]; $v$ is the average groundwater velocity in the direction of flow [Length $\cdot$ time $^{-1}$ ]; $D$ is the coefficient of diffusion and dispersion of the element in the fluid phase [Length ${ }^{2} \cdot$ Time $^{-1}$ ]; $\phi$ is the fraction of the total slow desorbing chemical present; $R_{d}$ is the retention factor; $t$ is the time coordinate [Time]; $x$ is the space coordinate [Length]; and $k_{\text {fast }}$ and $k_{\text {slow }}$ are the first-order rate constants describing the release rates for "Fast" and "Slow" desorbing chemicals, respectively [time ${ }^{-1}$ ]. The initial fast release, described by $k_{\text {fast }}$, occurs during the first few days after fracturing (fast desorption) and is followed by a slower stage, $k_{\text {slow }}$ term, which can take months or years (slow desorption).
Given the geometric characteristics of the system [Balashov et al., 2015] and the average physical-chemical conditions of the same [Ma et al., 2018], the transport equation can be simplified as follows (Eq. (2)):

$$
\begin{aligned}
C= & \frac{C_{0}}{2} \cdot \operatorname{erfc}\left[\frac{4}{\sqrt{\left(v / R_{d}\right)} \cdot t}-1.34 \cdot \sqrt{\left(v / R_{d}\right)} \cdot t\right] \\
& \cdot\left[\exp \left(-k_{\text {fast }} \cdot t\right)+\phi \cdot \exp \left(-k_{\text {slow }} \cdot t\right)\right]
\end{aligned}
$$

As shown in [Ma et al., 2018], this model allows fitting the experimental points for the different measurement days (see Fig. 1).

The Coefficient of Determination $\left(\mathrm{R}^{2}\right)$ for the different compounds was determined in order to define how close the sampling data fitted this modelling line. $\mathrm{R}^{2}$ accounted for more than 0.98 (except for phenol, which is explained by its high solubility in a higher temperature environment). This value indicates that our model properly describes the evolution of concentrations and the dynamic transport. The same applies to the rest of the criteria used: the Nash-Sutcliffe efficiency $E$ (NSE) exceeds 0.99 in all cases, as occurs with the index of agreement $d$ and the Pearson's $R$.

The accurate model fitting obtained also allowed us to conclude that, in this particular case, the introduction of additional processes, such as biodegradation, is not required to explain the behaviour of the system, thereby simplifying the model.

\subsubsection{Return water volume model}

Despite the great variability in the volume of the returned water in shale gas extraction wells, analysis of the data from the study by Hayes in 2009 shows that the temporal behaviour of such water can be grouped depending on whether the wells are horizontal or vertical.

Based on the experimental data of volumes (Table 1 at 1, 5, 14 and 90 days) from the horizontal wells [Hayes, 2009], an empirical expression for modelling the evolution of the volume of return water is given in Eq. (3) [Ma, 2018]:

$V(t)=a_{1}+\frac{a_{2} \cdot \ln (t)}{t^{a_{3}}}$

In which $V(t)$ is the volume of water $\left(\mathrm{m}^{3}\right)$ generated over a period of $t$ days and $a_{1}, a_{2}$ y $a_{3}$ are the fitting parameters.

Given the small number of wells for which a complete series of data is available, confidence intervals were determined for a sigma value of 1 (confidence value of 0.68 ) and 2 (confidence value of 0.95 ) by applying Student's t Distributions, since the number of data is insufficient to accept

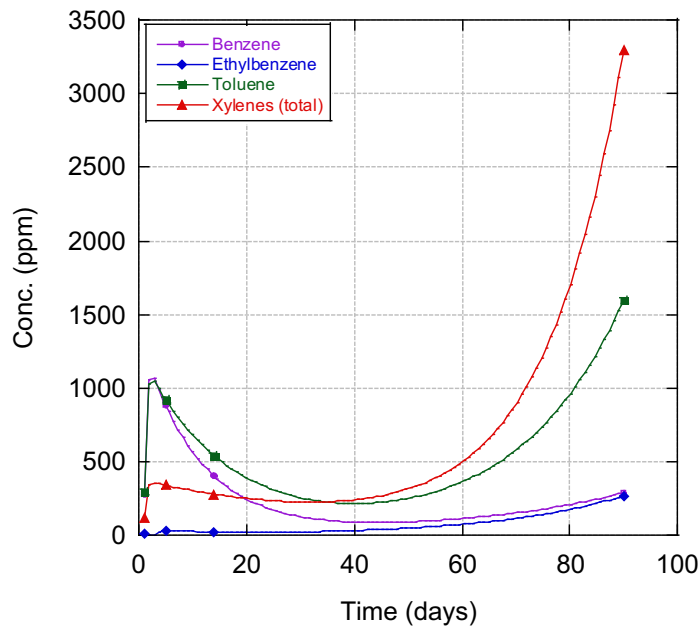

Fig. 1. Fitting for well $\mathrm{F}$ with the desorption model of two compartments first-order rate constants (model given by Eq. (2)). 
Table 1

Accumulated volume of flowback and produced water for horizontal wells.

\begin{tabular}{|c|c|c|c|c|c|c|c|c|}
\hline \multicolumn{9}{|c|}{ Horizontal well } \\
\hline Time ( day $^{\mathrm{a}}$ ) & $C\left(\mathrm{~m}^{3}\right)$ & $\mathrm{D}\left(\mathrm{m}^{3}\right)$ & $E\left(m^{3}\right)$ & $\mathrm{F}\left(\mathrm{m}^{3}\right)$ & $G\left(m^{3}\right)$ & $\mathrm{K}\left(\mathrm{m}^{3}\right)$ & $M\left(m^{3}\right)$ & $\mathrm{O}\left(\mathrm{m}^{3}\right)$ \\
\hline 1 & 525.93 & 453.75 & 1360.93 & 520.21 & 193.81 & 914.34 & 2610.41 & 815.76 \\
\hline 5 & 1534.55 & 1284.14 & 3232.21 & 1721.83 & 1191.29 & 1274.44 & 2851.44 & 3052.87 \\
\hline 14 & 2542.37 & 1580.02 & 3912.68 & 1960.47 & 1982.73 & 1506.09 & 3135.71 & \\
\hline 90 & & 1778.27 & 4082.79 & 2768.45 & 2969.41 & & & \\
\hline
\end{tabular}

${ }^{a}$ Days since the hydraulic fracturing event.

the normality hypothesis (for more details see Appendix B). The results are shown in Fig. 2 and Table 2.

The instantaneous return water volumes are obtained from the fits and the derivative of expression (3). The results are shown in Fig. 3, which indicates mean volumes and confidence intervals for each day. Note that negative volumes were represented as 0 , thus using the physical meaning of this parameter.

\subsubsection{Concentration of organic compounds in the tank model}

Measurement the pollutant concentration in surface wastewater storage structures involves the study of the temporal evolution of both the volume of flowback returned to the surface $\left(V_{f}(t)\right)$ and the pollutant concentration in these waters $\left(C_{f}^{\alpha}(t)\right)$ (see Fig. 4). Expressions 4 and 5 allow us to calculate the total mass of pollutant as a function of time, as well as the variation of the concentration.

$M_{w}^{\alpha}(t)=\int_{t \ddot{E}=0}^{t} C_{f}^{\alpha}(t \prime) \cdot V_{f}\left(t^{\prime}\right) \cdot d t^{\prime}$

$C_{w}^{\alpha}(t)=\frac{\int_{t \ddot{E}=0}^{t} C_{f}^{\alpha}\left(t^{\prime}\right) \cdot V_{f}\left(t^{\prime}\right) \cdot d t^{\prime}}{\int_{t \ddot{E}=0}^{t} V_{f}\left(t^{\prime}\right) \cdot d t^{\prime}}$

where $M_{w}^{\alpha}(t)$ is the mass of contaminant accumulated until time $t$ in the wastewater tank/pit [Mass]; $C_{w}^{\alpha}(t)$ is the concentration of contaminant at time $t$ in the wastewater tank/pit [Mass. Length ${ }^{-3}$ ]; $C_{f}^{\alpha}(t)$ is the concentration of contaminant at time $t$ in the flowback or produced water [Mass $\cdot$ Length $^{-3}$ ]; and $V_{f}(t)$ is the volume of flowback or produced water at time $t$ [Length ${ }^{3}$ ].

From the data available in Hayes' 2009 database changes in the concentrations of pollutants in flowback water can be tracked over time

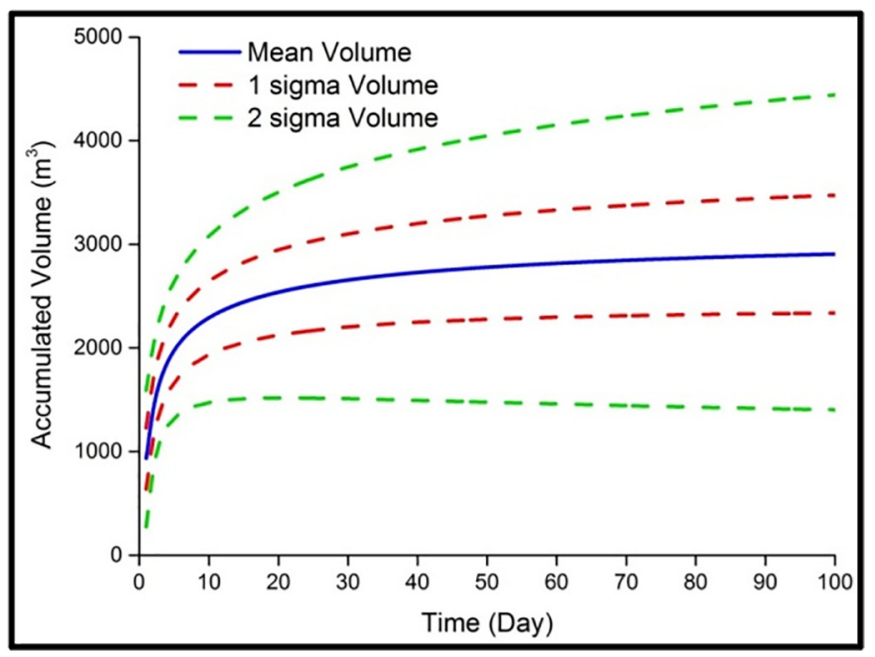

Fig. 2. Accumulated volume evolution. Mean values (blue curve) and confidence intervals for 0.68 (red curves) and 0.95 (green curves) confidence levels are shown. (For interpretation of the references to colour in this figure legend, the reader is referred to the web version of this article.)
[Ma et al., 2018]; however, such determination is not possible in the subsequent produced water phase, due to the scarcity of data. For the latter phase, we made a first estimate, and quantitative values for some of the compounds were obtained from the concentrations measured on day 90 (see Appendix A).

\subsection{Transport modelling in the unsaturated zone}

Proper risk assessment calls for evaluation of the processes associated with transport in the unsaturated zone and with the attenuation of organic compounds from storage tank leakage. This complex, multiprocess, environmental issue can include the following: source zone mass transfer due to simultaneous volatilisation and dissolution; advection, dispersion and diffusion in air and water phases influenced by time-variant infiltration, geological heterogeneity and preferential flows; volatility-driven gas-liquid (air-water/NAPL, i.e., non-aqueous phase liquids) phase partitioning, resulting in a dynamic interaction of dissolved-phase and vapour-phase plumes; phase partitioning due to sorption to solid phases and the air-water interface; and biodegradation and chemical reactions [Rivett et al., 2011].

Several modelling studies address the transport of organic compounds through the vadose zone before reaching an underlying aquifer. In this context, preliminary risk assessment studies are often subject to important data limitations. Consequently, they are commonly based on analytical models, which have minimal data requirements. In this context, an analytical model would allow us not only to understand the migration behaviour of chemicals, but to determine the dominant processes and their relevance for assessing the risks in an area with given environmental characteristics, in combination with the properties of the organic pollutants of interest. Although these models assume a series of simplifications, they are suitable for an initial assessment of the pollution risk. There are numerous analytical solutions available, and it is therefore necessary to select one that will adequately balance the data requirements and the process descriptions, in such a way that the model reflects those considered most relevant for the elements to be evaluated. Since many studies showed that the gas-phase transport in the unsaturated zone can be a dominant transport mechanism for volatile organic compounds (Organics) such as BTEX (benzene, toluene, ethylbenzene, and xylene), we selected an extension of the model described by Jury [Jury et al., 1983]. This model provides a onedimensional solution considering advection, diffusion, soil sorption and degradation in the aqueous and gas phases, while introducing a groundwater table at a given finite depth [Shan and Stephens, 1995].

Table 2

Parameter values of the fitting function for 0.68 and 0.95 levels of confidence.

\begin{tabular}{llllc}
\hline \multirow{2}{*}{ Curve } & \multicolumn{4}{l}{ Model parameters } \\
\cline { 2 - 5 } & $\mathrm{a}_{1}$ & $\mathrm{a}_{2}$ & $\mathrm{a}_{3}$ & $\mathrm{R}^{2}$ \\
\hline Mean & 932.49 & 812.46 & 0.13906 & 0.99911 \\
Min (0.68) & 637.85 & 859.54 & 0.18356 & 0.9997 \\
Max (0.68) & 1227.3 & 776.79 & 0.101 & 0.99857 \\
Min (0.95) & 275.72 & 1106.3 & 0.32758 & 0.99769 \\
Max (0.95) & 1590.4 & 677.65 & 0.019586 & 0.9975
\end{tabular}




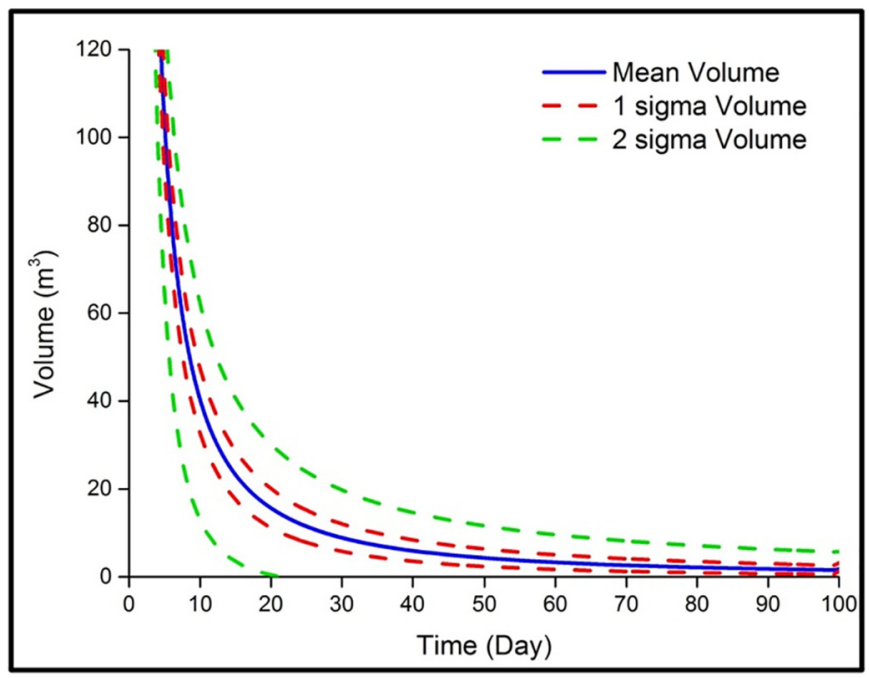

Fig. 3. Instantaneous return water volumes. Evolution of the mean values (blue solid curve) and confidence intervals for 0.68 (red dash curves) and 0.95 (green dash curves) confident levels are shown. (For interpretation of the references to colour in this figure legend, the reader is referred to the web version of this article.)

The model considers the following: linear equilibrium partitioning between vapour, liquid and adsorbed chemical phases; first-order degradation; and chemical movement to the atmosphere by volatilisation through the soil surface. The following transport mechanisms are assessed in this model: aqueous-phase advection and diffusion; gasphase diffusion; and adsorption of organics to solids. The model then provides a description of the transport in different phases, and the mass flux to groundwater can be estimated. The model considers a uniform contamination source located within a given depth interval in the vadose zone. By means of the principle of superposition [Jury et al., 1983; Shan and Stephens, 1995], the solution provided is suitable for more general problems where the initial contamination source is nonuniform. This model has been verified and validated by its authors with the numerical code VLEACH [Ravi and Johnson, 1997], and the results obtained are consistent with the numerical ones [Shan and Stephens, 1995].

Fig. 5 shows a schematic diagram of the model, on the assumption that all the organic chemicals are dissolved in the wastewater and that water spill advection is the only significant one-dimensional transport mechanism through the vadose zone.

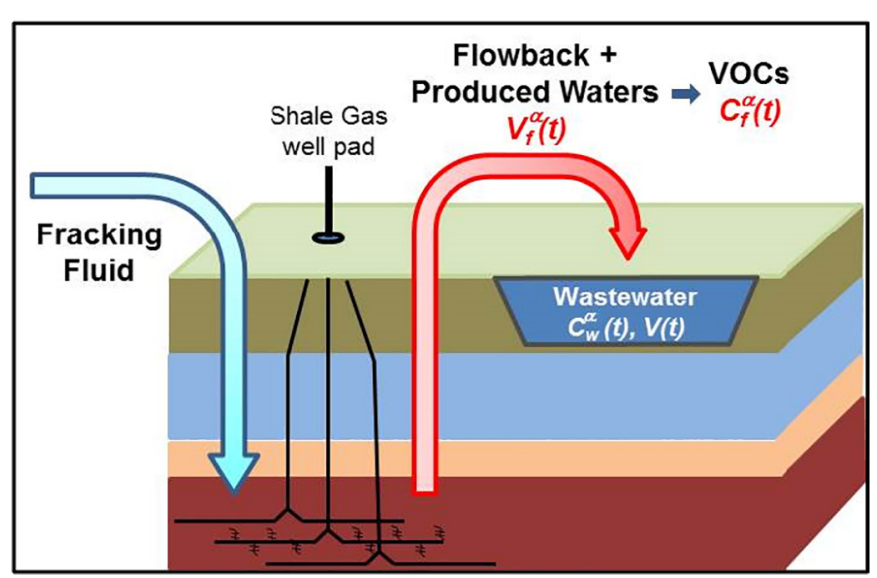

Fig. 4. Wastewater storage.

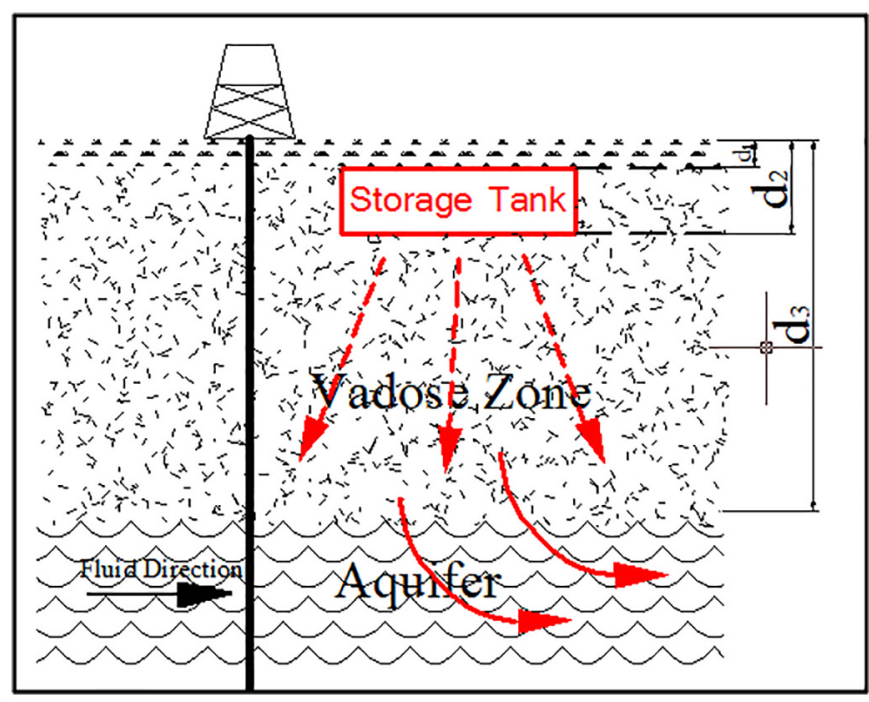

Fig. 5. Schematic view of wastewater release from the storage tank.

The analytical solution obtained by Shan and Stephens [Shan and Stephens, 1995] for a range of depth intervals can be expressed as follows:

$$
\begin{aligned}
C_{1}(z, t)= & \sum_{n=1}^{8}(-1)^{n} f_{1}\left(t, \alpha_{n}, \beta_{n}^{(0)}\right)+\sum_{m=1}^{\infty} C^{(m)}\left(0 \leq z \leq d_{1}\right) \\
C_{2}(z, t)= & C_{0} \cdot e^{-\lambda \cdot t}+\sum_{n=1}^{7}(-1)^{n} f_{1}\left(t, \alpha_{n}, \beta_{n}^{(0)}\right)-f_{2}\left(t, \alpha_{8}, \beta_{8}^{(0)}\right) \\
& +\sum_{m=1}^{\infty} C^{(m)}\left(d_{1} \leq z \leq d_{2}\right) \\
C_{2}(z, t)= & \sum_{n=1}^{6}(-1)^{n} f_{1}\left(t, \alpha_{n}, \beta_{n}^{(0)}\right)+f_{2}\left(t, \alpha_{7}, \beta_{7}^{(0)}\right)-f_{2}\left(t, \alpha_{8}, \beta_{8}^{(0)}\right) \\
& +\sum_{m=1}^{\infty} C^{(m)}\left(d_{2} \leq z \leq d_{3}\right)
\end{aligned}
$$

$f_{1}\left(t, \alpha_{n}, \beta_{n}^{(0)}\right)$ and $f_{2}\left(t, \alpha_{n}, \beta_{n}^{(0)}\right)$ are shown in Appendix C.

The model also allows the calculation of the flux and mass required for risk assessment. The mass flux rate to groundwater $\left(\mathrm{F}_{\mathrm{W}}\right)$ and to the atmosphere $\left(\mathrm{F}_{\mathrm{A}}\right)$ can be obtained directly from the previous solutions in the vadose-atmosphere $(z=0)$ and vadose-groundwater $\left(z=d_{3}\right)$ interfaces and are given by:

$F_{W}=\frac{v_{L}}{R_{L}}\left(C_{3}\right)_{z=d_{3}} ; F_{A}=-\frac{D_{G}}{R_{G}}\left(\frac{\partial C_{1}}{\partial z}\right)_{z=0}$

Time-dependent cumulative mass to the groundwater and to the atmosphere are obtained by the integration of the above equations with respect to time:

$$
\begin{aligned}
& M_{w}(\%)=\left(\frac{v_{L}}{R_{L}} \cdot \int_{0}^{t}\left(C_{3}\right)_{z=d_{3}} d t\right) / M_{t} \\
& M_{A}(\%)=\left(\frac{D_{G}}{R_{G}} \cdot \int_{0}^{t}\left(\frac{\partial C_{1}}{\partial z}\right)_{z=0} d t\right) / M_{t}
\end{aligned}
$$

\subsubsection{Modelling parameters}

The selection of parameters at such an early stage is not straightforward because of the limited data available or because studies are done 
on generic sites. In this regard, it is often necessary to resort to values given in the literature [Troldborg et al., 2009].

Accordingly, a variation of three orders of magnitude is considered for the recharge rate to contain sufficiently comprehensive environmental conditions in the fracturing operation zone. This allows us to determine the influence of the recharge rate on organic compound transportation in the unsaturated zone. Thus, a recharge rate value of $0.01 \mathrm{~cm} /$ day represents the situation in an arid area; $0.10 \mathrm{~cm} / \mathrm{day}$, a semi-arid area; and $1.00 \mathrm{~cm} /$ day, a humid zone. However, with respect to substances with higher solubility in water, such as acetophenone and phenol, the value range must be pre-tested in order to ensure the accuracy of the model.

The other values considered are set out below. These are regarded as adequate in a generic location in Spain. Half-buried tank-type surface disposal storage is assumed, with a leak in the underground section at a depth of between 50 and $150 \mathrm{~cm}$, and a water table at a depth of $10 \mathrm{~m}$ from the surface. The values for soil bulk density, porosity, water content, and organic content are $1.35 \mathrm{~g} / \mathrm{cm}^{3}, 0.5,0.2$ and $0.0125 \mathrm{respec}-$ tively. We also considered it unnecessary to introduce a ventilation system in the target area and we used a gas advection velocity of zero. All the parameters considered are listed in Table 3.

\section{Results and discussion}

\subsection{Concentration in tank}

Once the temporal evolution of both the volume of the return water and concentration of the organic compounds present in it had been determined using the results associated with "Fast" and "Slow" desorption, as described in [Ma et al., 2018], we obtained the accumulated concentration of the organic groups in the storage tanks via expression (4). The results for the different families of compounds, as well as the errors associated with them, are given in Appendix A.

Table 4 shows the results, with respect to time, of the estimation of the maximum concentrations of the covered substances in the storage tank (average and confidence interval values) for the first 1000 days after the hydraulic fracturing event.

The chemical concentration in the produced water was higher than in the flowback fluid. However, the volume of the latter was of orders of magnitude higher than that of the former (see Table A.3 in Appendix A). Therefore, the maximum concentration of the tank occurred in the first two months after hydraulic fracturing.
In the temporary sampling carried out by Hayes [Hayes, 2009], it was not possible to satisfactorily carry out the model adjustment for phenol and for R-Benzene to obtain the evolution of their concentrations in the return water [Ma et al., 2018]. We therefore decided to use a normalized value of $100 \mathrm{ppm}$ as average concentration value. In this regard, once the concentration of these substances in the tank had been determined, the results were directly extrapolated to experimental values. For the deviation value of 1-sigma, the deviation associated with the experimental data in the different wells for the time of maximum concentration was considered, obtaining a value of $199.36 \mathrm{ppm}$ for phenol and 210.38 ppm for R-Benzene.

Given that the concentrations of the pollutants in the storage tank vary with time and that the consequences are a function of these, the results presented in this section are expressed as a percentage of the concentration at the time of the leakage.

\subsection{Vertical transportation results}

In this study we sought to examine how external parameters (especially liquid advection velocity, $V_{L}$ ) and physico-chemical properties work together and whether they mutually enhance the transport of organic compounds in the vadose zone. For cumulative mass percentage a semi-logarithmic plot (logarithmic time factor item in X-axis and mass percentage in Y-axis) was selected for a proper graphical representation of the results, given that their estimation was calculated for a timing range defined by the values $(t=10,100,1000,10,000$ days after leakage). Under a range of liquid advection velocity conditions (different column represents different recharge rate value), Table 5 shows the mass percentage evolution of three dynamic regions (vadose, groundwater and atmosphere), where the blue and the purple dots indicate the mass percentage of chemicals reaching the atmosphere and groundwater table, respectively.

Table 6 shows the predicted concentration profiles, ranging from 10 days to tens of years after the leakage. In addition, both air and soil concentrations of the organic compounds are shown in Tables 7 and 8 as a function of a set of recharge rates and leaking times (mean value $(\bar{m})$ and mean plus 1 sigma dispersion $(1 \sigma)$ ).

The groups of organic compounds studied that are present in both the flowback and produced waters showed distinct behaviours in the soil. Once a hypothetical discharge occurs, its evolution depends on the solubility and volatility of the organic compounds involved. Our results were classified on the basis of these characteristics (non-volatile

Table 3

Model parameters.

\begin{tabular}{|c|c|c|c|c|c|c|c|c|c|}
\hline \multirow[t]{2}{*}{ Parameter } & \multirow[t]{2}{*}{ Description } & \multicolumn{8}{|c|}{ Organic chemicals } \\
\hline & & Acetophenone & Benzene & Phenol & TEX & TMB & R-Benzene & NAPH & PAHs-NAPH \\
\hline$k_{o c}\left(\mathrm{~cm}^{3} / \mathrm{g}\right)$ & Liquid-solid partitioning coefficient for soil carbon & 52 & 146 & 187 & 366 & 624 & 1738 & 1540 & 63,384 \\
\hline$K_{H}$ & Henry's constant & 4.25E-04 & 2.3E-01 & $1.36 \mathrm{E}-05$ & 2.7E-01 & 2.6E-01 & $5 \mathrm{E}-01$ & $1.8 \mathrm{E}-02$ & $3.95 \mathrm{E}-04$ \\
\hline$D_{w}\left(\mathrm{~cm}^{2} /\right.$ day $)$ & Water diffusion coefficient & 0.75 & 0.89 & 1.17 & 0.84 & 0.68 & 0.65 & 0.73 & 0.60 \\
\hline$D_{a}\left(\mathrm{~cm}^{2} /\right.$ day $)$ & Air diffusion coefficient & 5633.28 & 7732.79 & 7205.76 & 5961.61 & 5261.76 & 4950.72 & 5227.18 & 3862.08 \\
\hline$\rho_{b}\left(\mathrm{~g} / \mathrm{cm}^{3}\right)$ & Bulk density & \multicolumn{8}{|c|}{1.35} \\
\hline$d_{1}(\mathrm{~cm})$ & Depths to the top source & \multicolumn{8}{|c|}{50} \\
\hline$d_{2}(\mathrm{~cm})$ & Depths to the bottom source & \multicolumn{8}{|c|}{150} \\
\hline$d_{3}(\mathrm{~cm})$ & Groundwater table & \multicolumn{8}{|c|}{1000} \\
\hline$v_{L}(\mathrm{~cm} /$ day $)$ & Liquid advection velocity & \multicolumn{8}{|c|}{$0.01,0.1,1.0$} \\
\hline$v_{G}(\mathrm{~cm} /$ day $)$ & Gas advection velocity & \multicolumn{8}{|c|}{0} \\
\hline$\phi\left(\mathrm{cm}^{3} / \mathrm{cm}^{3}\right)$ & Porosity & \multicolumn{8}{|c|}{0.5} \\
\hline$\theta\left(\mathrm{cm}^{3} / \mathrm{cm}^{3}\right)$ & Water content & \multicolumn{8}{|c|}{0.2} \\
\hline$\alpha_{L}(\mathrm{~cm})$ & Liquid dispersivity & \multicolumn{8}{|c|}{0} \\
\hline$\alpha_{G}(\mathrm{~cm})$ & Gas dispersivity & \multicolumn{8}{|c|}{0} \\
\hline$\lambda\left(\mathrm{d}^{-1}\right)$ & Decay rate & \multicolumn{8}{|c|}{0} \\
\hline$f_{o c}$ & Fraction organic content & \multicolumn{8}{|c|}{0.0125 [ITRC, 2015] } \\
\hline$K_{S G}$ & Solid-gas distribution & \multicolumn{8}{|c|}{$2 K_{S L}$} \\
\hline$K_{S L}$ & Solid-liquid & \multicolumn{8}{|c|}{$K_{S L}=K_{o c} f_{o c}$} \\
\hline
\end{tabular}


Table 4

Maximum estimated concentration (mean and confidence interval values) within 1000 days of fracturing operations.

\begin{tabular}{|c|c|c|c|c|c|c|c|c|}
\hline & Acetophenone & Benzene & Phenol & TEX & TMB & R-Benzene & $\mathrm{NAPH}$ & PAHs-NAPH \\
\hline Mean (ppm) & 2.5 & 82.4 & 100 & 110.5 & 7.7 & 100 & 0.18 & 1.1 \\
\hline 1 sigma & 3.9 & 158.3 & 199.36 & 227.1 & 12.3 & 210.38 & 0.32 & 1.8 \\
\hline
\end{tabular}

and volatile organic substances). The results are presented, interpreted and discussed below.

\subsubsection{Non-volatile organic substances}

The low solubility of the organic compounds, together with the high value of $\mathrm{f}_{\mathrm{oc}}$ (fraction organic content) in the soil, causes them to be primarily adsorbed in the solid phase.

Thus, the estimated results for acetophenone (Figures $A_{M 1}, A_{M 2}$ and $A_{M 3}$ in Table 5) show that almost all the compounds are absorbed in the soil organic matter and that the dissolution of the substances in water is not a relevant phenomenon within the first 100 days. The estimated concentration curves at 10 and 100 days (Figures $A_{C 1}$ and $A_{C 2}$ in Table 6) also reveal that the three predicted concentration curves almost overlap, despite the different conditions considered. This observation implies that, under the conditions tested, the recharge rate does not influence the transport of pollutants within a short period of migration.

Over time, acetophenone in the vadose zone advances towards the saturated zone, with very slow diffusion throughout the process due to the value of its $\mathrm{K}_{\mathrm{H}}$. Given this feature, the pollution plume practically does not expand along its advance. Therefore, when the contaminant reaches the water table, the percentage that passes to the groundwater increases rapidly until virtually all of it dissolves in the groundwater. The comparison of results (Figures $A_{M 1}, A_{M 2}$ and $A_{M 3}$ in Table 5 and Figures $A_{C 3}, A_{C 4}$ in Table 6 ) shows that the greater the recharge rate and the longer the substance migrates, the more chemicals are dissolved into the liquid phase, thus implying a potential acceleration of migration to the aquifer layer. As the recharge rate is $0.01 \mathrm{~cm} /$ day (arid conditions), the groundwater mass percentage does not change significantly within the period under consideration. When the rate falls between 0.1 and $0.7 \mathrm{~cm} /$ day (semi-arid and humid regions), the groundwater mass curve shows a marked rise at 4000 and 1600 days, respectively. For the long-term analysis, the recharge rate plays a key role in the vertical transportation model.

In addition, the retention factor becomes progressively more important for organic chemical transportation over time. It explains why, when compared to other factors calculated under the shorter transportation period profiles $\left(A_{C 1}, A_{C 2}\right.$ and $A_{C 3}$ in Table 6$)$, the maximum concentrations or organic compounds are smaller and the curves at 10000 days $\left(A_{C 4}\right.$ in Table 6$)$ are wider. These observations are explained by diffusive transport behaviours.

Finally, the concentration profiles of acetophenone-a good example of an organic compound with low volatility-under the different periods of migration $\left(A_{M 1}, A_{M 2}\right.$ and $A_{M 3}$ in Tables 5 and 7$)$, reveal that volatilisation can be discarded.

The same behaviour is observed for the Phenol and PAHs-NAPH families. Their solubility in water is limited at normal temperature and pressure $\left(20^{\circ} \mathrm{C}\right.$ and $\left.1 \mathrm{~atm}\right)$ but above $68{ }^{\circ} \mathrm{C}$ they are fully water-soluble [NCBI, 2017]. For substances with greater solubility, a value of $0.10 \mathrm{~cm} /$ day for the maximum liquid advection velocity is considered in the model. Figures $\mathrm{C}_{\mathrm{M} 2}$ and $\mathrm{C}_{\mathrm{M} 3}$ (Table 5) show how the chemical compounds reach the water table. Of note is the longer timeframe required in the latter ( $t=400,4000,40,000,400,000$ days). The concentration in groundwater is altered only in Figure $\mathrm{C}_{\mathrm{M} 3}$. It is possible that consideration of migration only in an arid and semi-arid zone $\left(\mathrm{V}_{\mathrm{L}}=\right.$ $0.01 \mathrm{~cm} /$ day and $\mathrm{V}_{\mathrm{L}}=0.10 \mathrm{~cm} /$ day) results in a delay in the desorption phenomenon.

For NAPH, Henry's constant value is $1.8 \mathrm{E}-02$. This explains why in the results shown in Table 5, Figures $G_{M 1}$ and $G_{M 2}$, part of the total amount of the substances enters the atmosphere in arid and semi-arid areas.
However, most compounds in this group, including PAHs-NAPH, are absorbed in the solid phase (Table 5, Figures $H_{M 1}$ and $H_{M 2}$ ). Over time, more and more substances dissolve into liquid and eventually migrate to the aquifer (Table 5, Figures $G_{M 1}, G_{M 2}$ and $H_{M 3}$, and Table 6, Figures $G_{C 4}$ and $H_{C 4}$ ).

\subsubsection{Volatile organic substances}

Similar to the results for acetophenone, the dissolution of benzene (Figures $B_{M 1}, B_{M 2}$ and $B_{M 3}$ in Table 5 ) in groundwater is not an evident phenomenon for the first 1000 days for any of the scenarios contemplated (arid, semi-arid and humid). However, in contrast to acetophenone, benzene is a volatile chemical and, therefore the gas phase is occupied in a higher proportion. In all of the scenarios tested, a fraction of the compound reaches the atmosphere during the first months after the leakage.

It is assumed that the contaminated mass in the gas phase for arid $\left(V_{L}=0.01 \mathrm{~cm} /\right.$ day $)$ and semi-arid $\left(V_{L}=0.1 \mathrm{~cm} /\right.$ day $)$ areas exceeds the contents adsorbed after only one year. Three years after the leakage, the volatilisation growth trend slowly decreases in this dynamic equilibrium state until most of the chemical (almost 90\%) is transferred to the atmosphere. The physico-chemical behaviour of benzene implies that almost all of it is released into the atmosphere or groundwater about thirty years after the leakage for all the scenarios considered. Estimations (see Figure $B_{M 3}$, in Table 5) in humid areas $\left(V_{L}=1 \mathrm{~cm} /\right.$ day) indicate that, after 1000 days, benzene dissolved in groundwater shows a positive trend until a dynamic equilibrium between water and vapour phase is reached. Comparing the estimated results (Figures $B_{M 1}, B_{M 2}$ and $B_{\mathrm{M} 3}$, I n Table 5) under the different recharge rates and the increase in precipitation (from $0.01 \mathrm{~cm} /$ day to $1 \mathrm{~cm} /$ day), the mass percentage in liquid phase would rise (from $0.1 \%$ to $55 \%$ ), while the percentage in gas would decrease correspondingly (from $90 \%$ to $45 \%$ ).

For TEX, TMB and R-Benzene, classified as volatile organic compounds (VOCs), cumulative mass percentage results show similar behaviours to the corresponding benzene compounds, i.e., the longer the leaks, the less recharge, the more materials volatilise. Estimated gas mass percentage of TEX, TMB and $R$-Benzene in the arid area $\left(V_{L}=0.01 \mathrm{~cm} /\right.$ day $)$ at 10000 days reaches $82 \%, 78 \%$ and $70 \%$, respectively. However, when the recharge rate is $1 \mathrm{~cm} / \mathrm{day}$, the content of TEX, TMB and R-Benzene in the gas phase decreases to $45 \%, 40 \%$ and $50 \%$, respectively.

The dissolved organic chemicals present in the wastewater spills are subject to vertical advective processes associated with the recharge water, until this eventually reaches the water table. In addition to this physical movement, dissolved organic chemicals would be adsorbed/ desorbed and/or volatilise to other phases (soil or gas interface) depending on their volatility, until the lower and upper limits of the vadose zone are reached. TMB $\left(K_{H}=0.26\right)$ and benzene $\left(K_{H}=0.23\right)$ have similar values of Henry's constants. For arid conditions, while TMB, in principle, is only slightly more volatile than benzene, under complex transport conditions involving many other factors, such as water solubility, which is greater for benzene than for TMB, about $90 \%$ of benzene is released to the atmosphere in the gas phase at 10000 days (Figure $B_{M 1}$ in Table 5), compared with only $78 \%$ of TMB (Figure $\mathrm{E}_{\mathrm{M} 1}$ in Table 5).

Regarding VOCs, gas diffusion is usually the dominant transport mechanism in the case of dry soils [Shan and Stephens, 1995], and the recharge rate is proportional to the migration rate but inversely proportional to volatility. VOC vaporization into the gas phase is more effective than dissolution in water. The results therefore indicate that increasing the ventilation in the affected area may be the most effective method to remove VOCs in the short term. 


\subsection{Discussion of the results}

The combination of the results of this analysis with the ranges of estimated concentrations for different times allows systematic studies of the expected exposure to each of the groups. These studies, in turn, combined with the toxicity values of each of the elements, allow the ranking of the contaminants with respect to the risk they pose for the environment and human health.

Our results indicate that volatile and non-volatile compounds show a delay in reaching the groundwater. This time has been estimated to span months and varies depending on the specific substance. The timeframe involved therefore provides some margin for decisionmaking and the implementation of remediation measures. However, volatile substances reach the atmosphere more quickly, thereby allowing a response in only a few tens of days.

Our findings on the contamination that occurs in the distinct environmental compartments (vadose zone, groundwater and atmosphere) allow us to compare the behaviours of each pollutant family under a range of environmental conditions. The effective concentration ranges associated with each family allow a first estimation of the most relevant compounds with respect to atmospheric and water pollution and the potential risk they pose for human health and the environment.

Risk assessment is commonly focused on exposure to chemicals in water [McKenzie et al., 2012]. However, our results indicate that, for volatile elements, the greater the aridity of the zone, the greater the need to include air pollution in this assessment. We identified benzene

Table 5

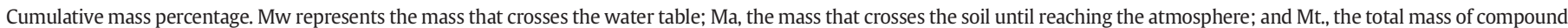

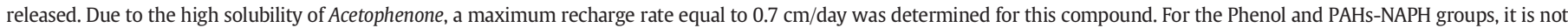
possible to establish concentrations that cross the water table for humid conditions because the combination of their $\mathrm{K}_{\mathrm{H}}$ and $\mathrm{f}_{\mathrm{oc}}$ values makes the numerical solution unstable.

\begin{tabular}{ccc}
\hline $\begin{array}{l}\text { Organic } \\
\text { compounds }\end{array}$ & 10 days & 100 days \\
\hline
\end{tabular}
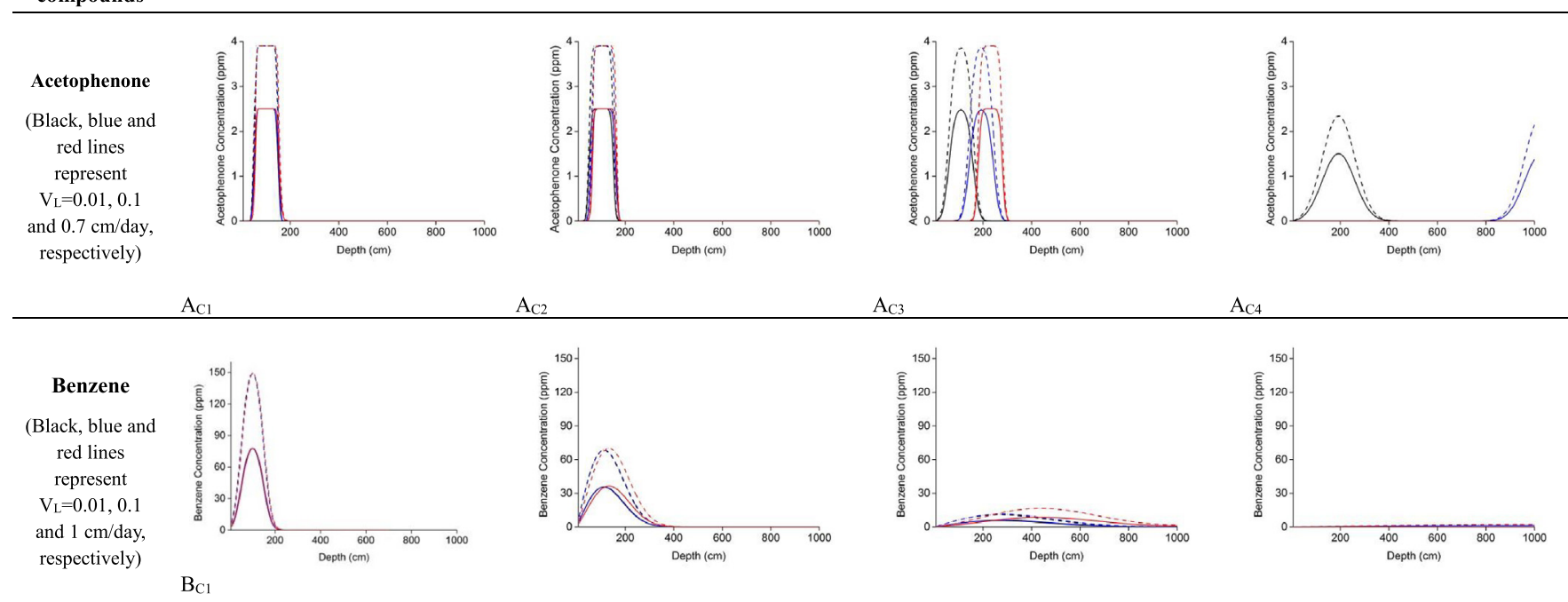

$\mathrm{B}_{\mathrm{C} 1}$

$\mathrm{B}_{\mathrm{C} 2}$
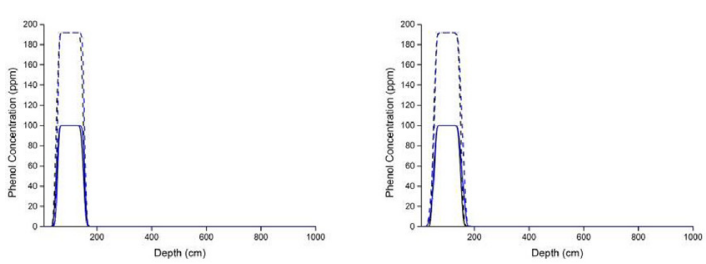

$\mathrm{C}_{\mathrm{C} 1}$

$\mathrm{C}_{\mathrm{C} 2}$

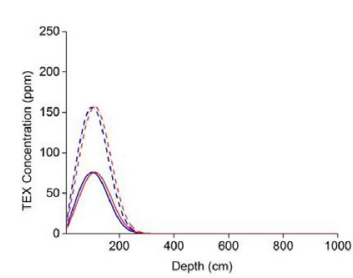

$\mathrm{D}_{\mathrm{C} 1}$
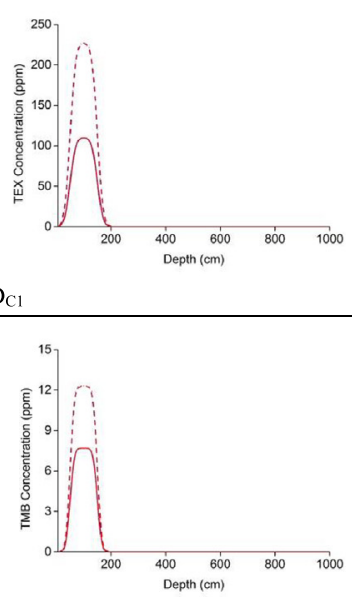

$\mathrm{D}_{\mathrm{C} 2}$

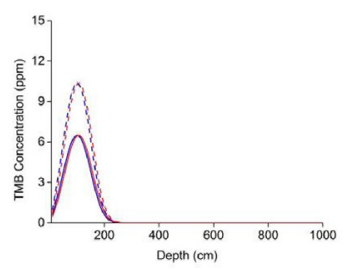

$\mathrm{E}_{\mathrm{C} 2}$
$\mathrm{B}_{\mathrm{C} 3}$

$\mathrm{B}_{\mathrm{C} 4}$

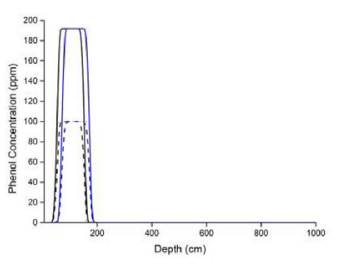

$\mathrm{C}_{\mathrm{C} 3}$

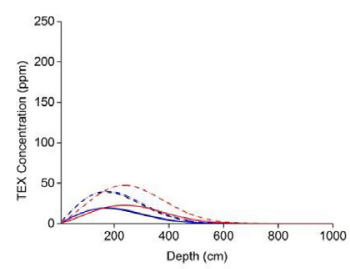

$\mathrm{D}_{\mathrm{C} 3}$

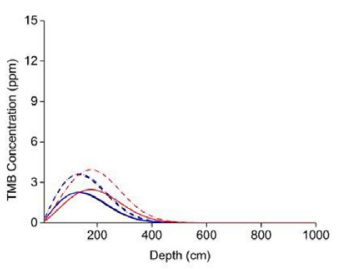

$\mathrm{E}_{\mathrm{C} 3}$

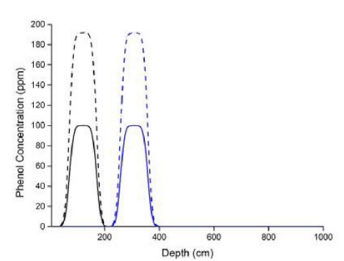

$\mathrm{C}_{\mathrm{C} 4}$

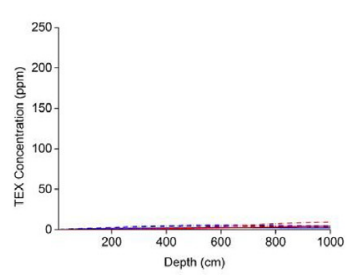

$D_{\text {C4 }}$

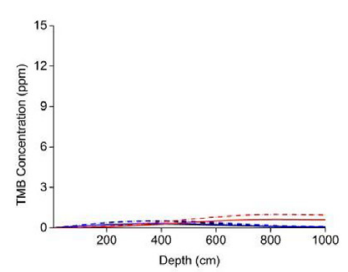

$\mathrm{E}_{\text {C4 }}$ 

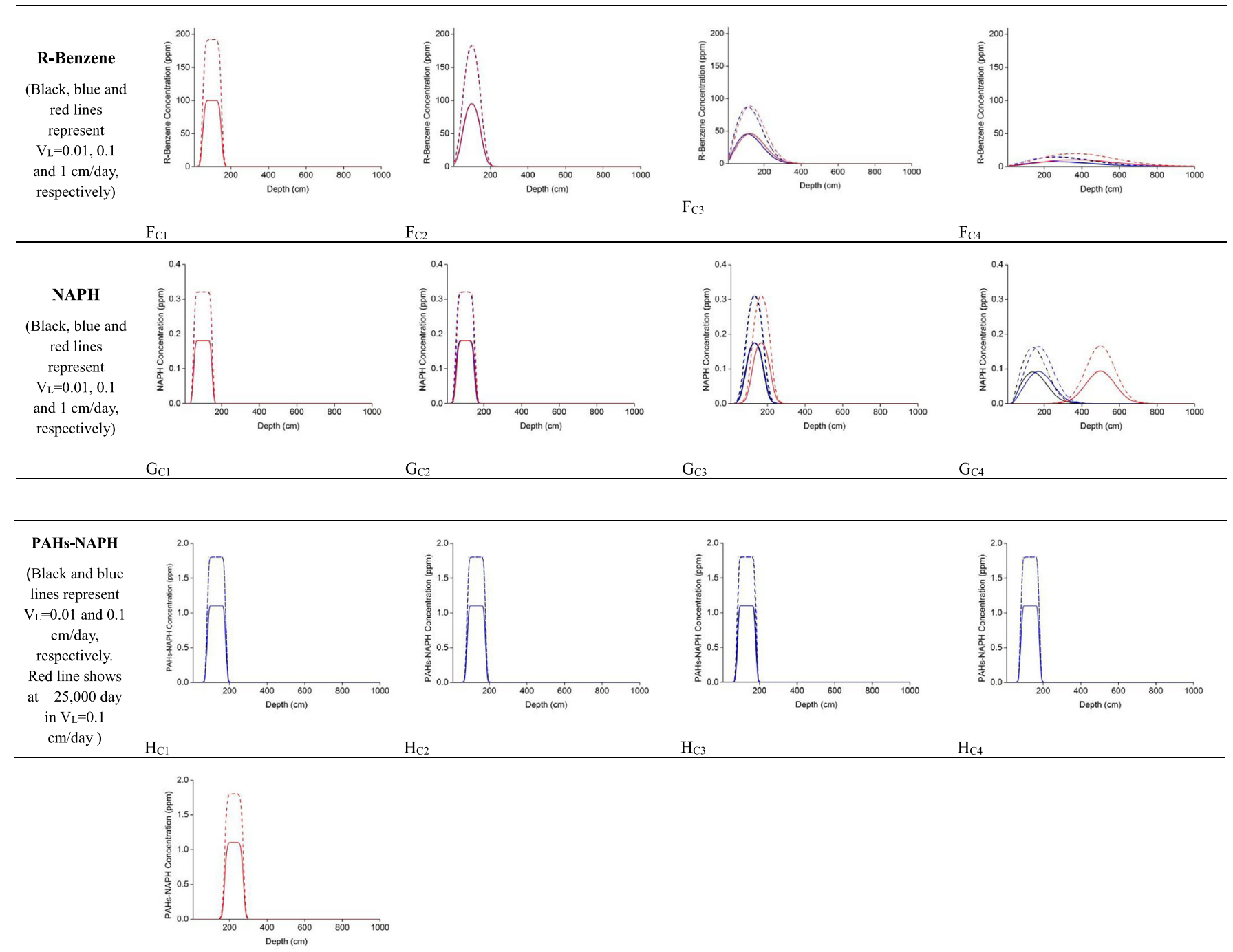

$\mathrm{H}_{\mathrm{C} 5}$

as the compound that presents the greatest volatilisation after a spill and, therefore, the compound that poses the greatest associated risk, given the maximum concentrations estimated in the storage facility. These results are corroborated by the experimental results obtained in the Barnet Shale basin, where over 4.7 million data points were taken for sampling VOCs to characterize the risks associated with air emissions from natural gas operations [McKenzie et al., 2012; Bunch et al., 2014]. Other initial assessments also identified VOCs as substances of concern, benzene being reported to pose the greatest risk [Ethridge et al., 2015]. Our results, which are derived from estimations of pollutant content in environmental compartments based on concentrations in the flowback and production waters samples rather than direct measures from these contaminants in the environment, corroborate those reports. Furthermore, our findings indicate that, in addition to the benzene family, the TEX and TMB families, whose concentration values in the area of the spill can exceed their Threshold Limit Values, should be considered as substances of concern.

In the case of non-volatile compounds, their impact is associated with the contamination of groundwater. In this regard, the approach used in this study considers the distinct site conditions (arid, semiarid and humid) and compounds of interest, thereby allowing an estimation of the time each one takes to reach the aquifer, as well as the shape of the arrival front. This information, together with the hydrogeological conditions of the aquifer, allows a reduction in the variance of risk estimates, as well as the introduction of factors associated with the conditions of the site into the estimation.

Here we provide estimations of the time taken by a variety of organic compounds to reach the water table. With adequate initial monitoring and remediation measures, such information can be used to facilitate the prevention of both carcinogenic and non-carcinogenic risks for human health. Taking into consideration the conditions of both the environment and the aquifer that the discharge reaches, our approach also allows calculation of a cut-off point of maximum spill volume at which no adverse effects from any exposure pathway can be expected.

In addition, the method described herein allows estimation of the evolution of both the composition of the flowback water and the distribution of the pollutant in the various phases of contamination.

In summary, our study: (1) provides a greater understanding of the mechanism by which external environmental variables (especially recharge rate) affect organic compound migration in the vadose zone; (2) predicts the behaviour of chemicals with respect to concentrations under a range of conditions; (3) provides an estimation of the time that chemicals can remain in the contaminated areas, and therefore identifies the phases of contamination with the greatest impact on human health; (4) determines the maximum risk limits for local residents directly through the concentrations of organic toxic compounds; and (5) estimates the composition of the water in the storage tank and the concentrations of organic compounds in environmental 
compartments as a function of time, thereby facilitating and improving risk management in the event of spills.

Here we provide new approaches for the assessment of the environmental, safety and health risks associated with the extraction of nonconventional fossil fuel resources by hydraulic fracturing [Veiguela et al., 2016] at local and larger scales. The model described herein offers a valuable tool for the management of shale gas exploitations and is expected to find further applications in similar scenarios.

\section{Conclusion}

Estimation of how the concentration of a series of contaminants in the tanks evolve, as well as the maximum concentrations reached within the first 1000 days after the hydraulic fracturing event, allowed us, in the event of any leakage, to gain insight into the expected concentrations of the organic compounds transported through the vadose zone until reaching an assumed aquifer. Our

Table 6

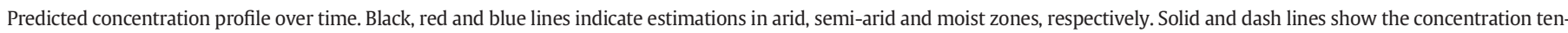
dency under the mean and 1 sigma confidence interval concentration.

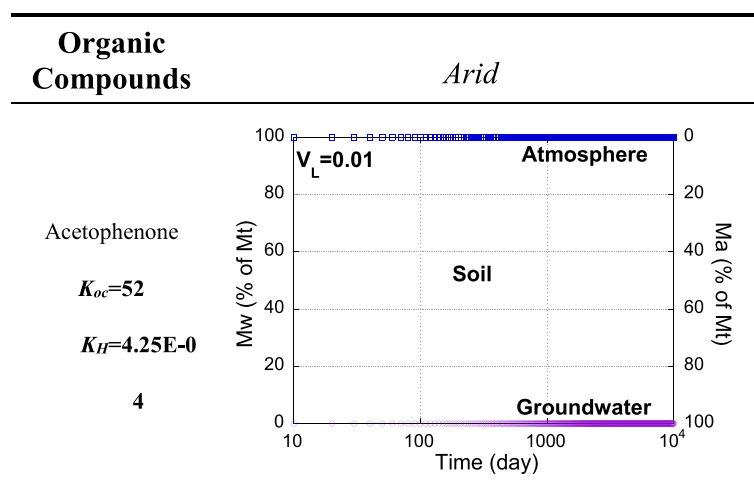

Aм1

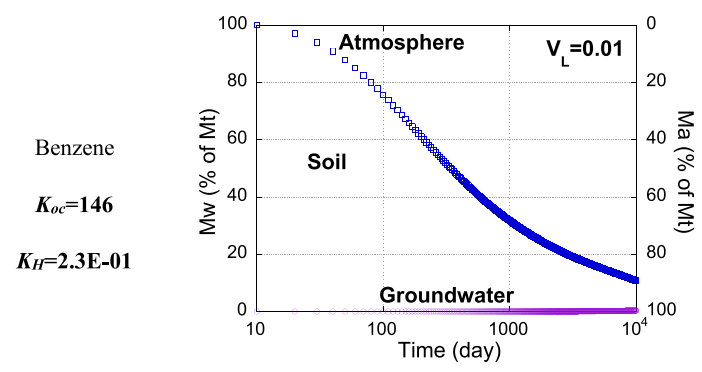

BM1

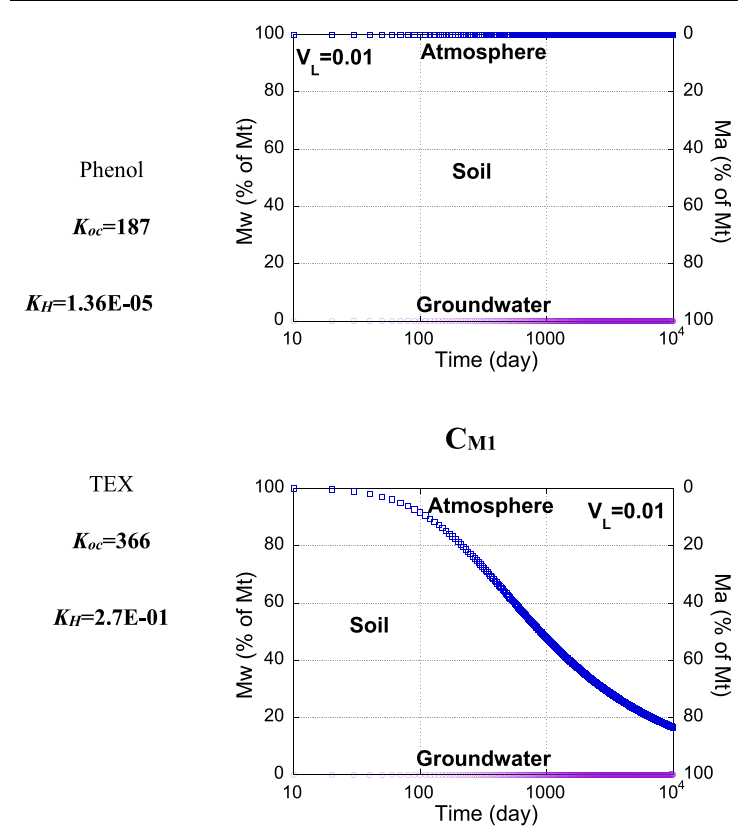

$\mathbf{D}_{\mathrm{M} 1}$
Semi-Arid

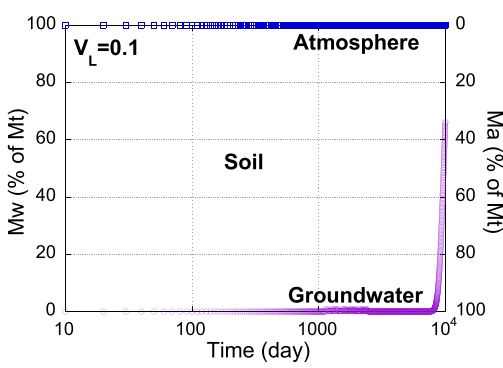

Aм2

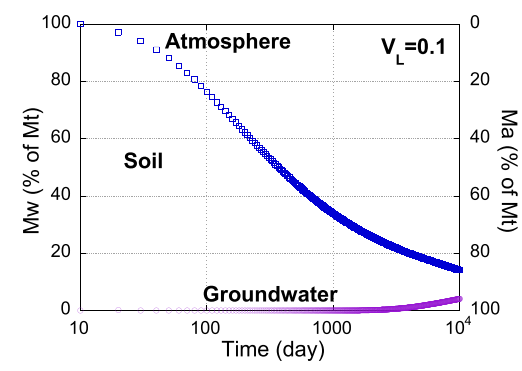

BM2

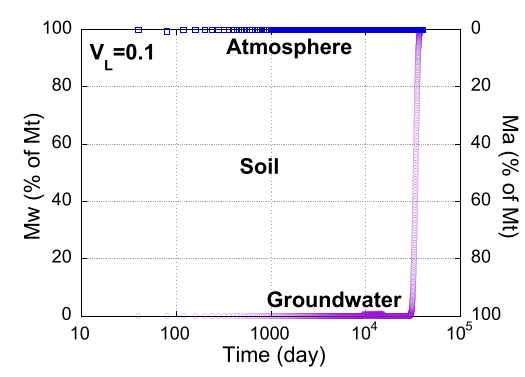

$\mathrm{C}_{\mathrm{M} 2} \mathrm{C}_{\mathrm{M} 3}$
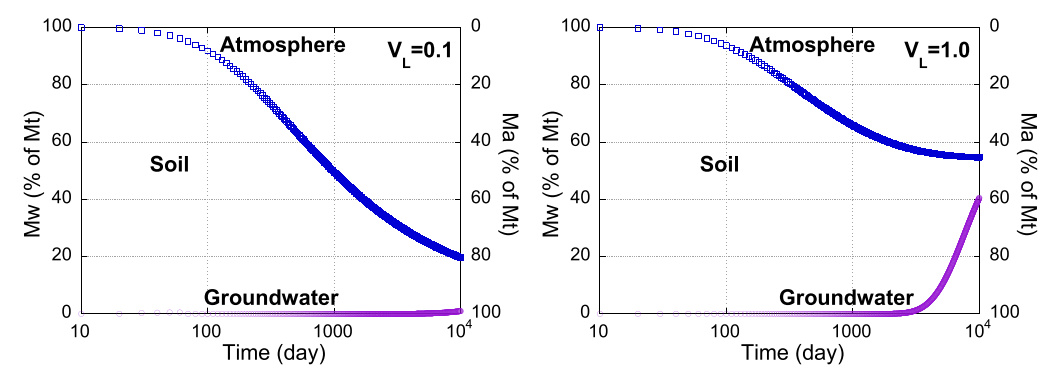

$\mathbf{D}_{\mathbf{M} 3}$ 

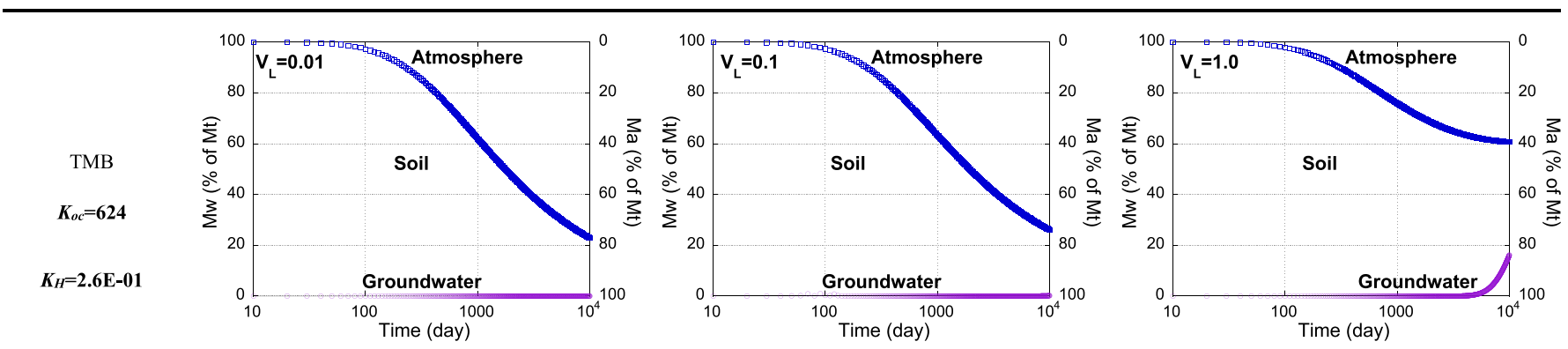

EM1

R-Benzene

$K_{\text {oc }}=\mathbf{1 7 3 8}$

$K_{H}=\mathbf{5 E}-01$

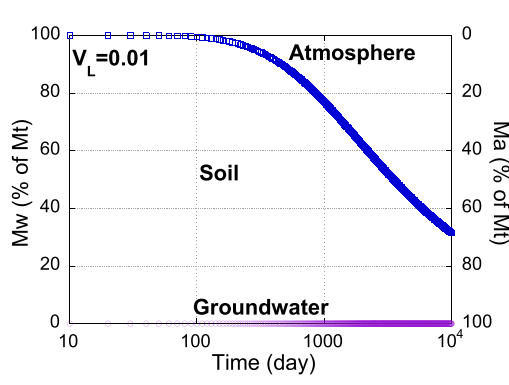

$\mathbf{E}_{\mathbf{M} 2}$

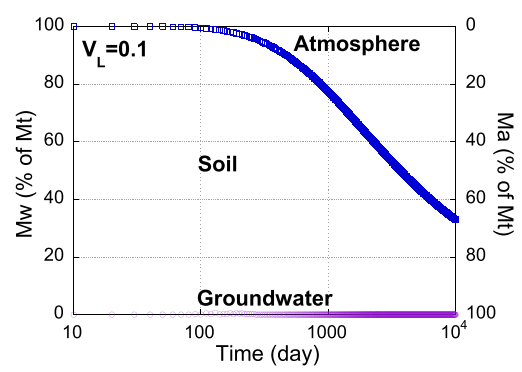

$\mathbf{E}_{\mathbf{M} 3}$

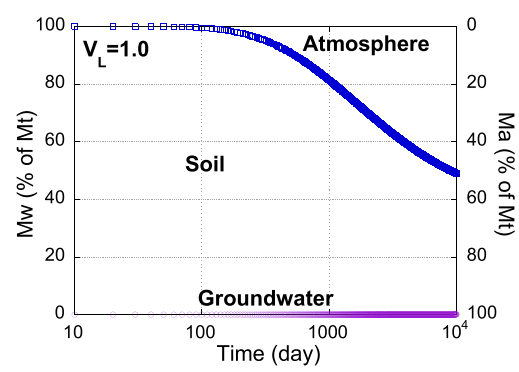

$F_{M 1}$

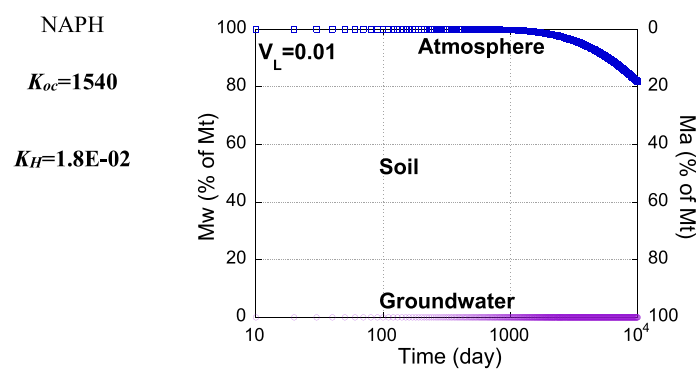

GM1

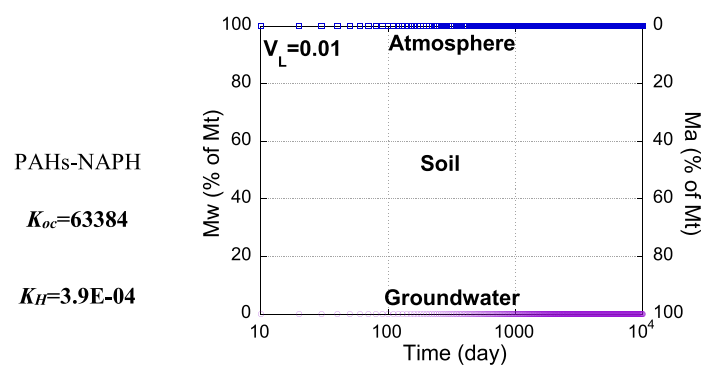

HM1
$\mathbf{F}_{\mathbf{M} 2}$

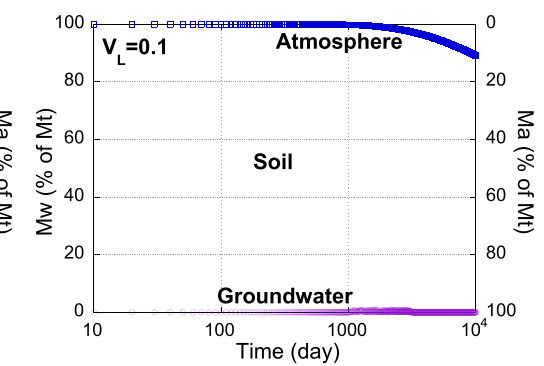

GM2

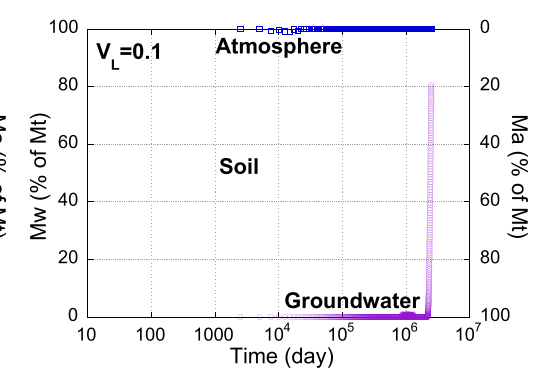

FM3 $_{3}$

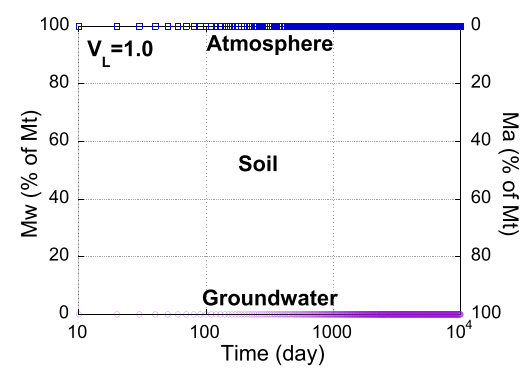

GM3 approach also facilitated estimations of the concentrations of these compounds in each environmental compartment as a function of the time when the spill occurred, and of the evolution of the spill on surface soil.

Afterwards, assuming that a spill occurs from the storage tank, analytical solutions allowed us to determine the impact of the recharge rate on the foreseen cumulative mass percentage and the concentration profile of the organic compounds in the vadose zone over time, considering the effect of environmental conditions, namely arid, semi-arid and humid.

The mass percentage results show that virtually all organic compounds for the conditions tested are adsorbed in the solid phase in the initial stage (i.e., within the first 100 days of the spill) in arid, semi-

Нм2 Нм3

arid and humid conditions. It should be noted that the recharge rate factor has a limited effect as desorption process in the short-term. On the basis of comparison of the curves of gas percentage of the different compounds, we conclude that, under the conditions tested, the greater the number of substances with a high Henry's constant value, the greater the volatility into the gas phase. Our approach has allowed us to rank the level of risk posed by the compounds. Benzene is placed at the top of this list, which is consistent with experimental data from other studies. In addition, we have also been able to determine that the volatilisation of a set of organic compounds identified in the study decreases when the prevailing conditions are humid. These estimations are valuable for the tailored fine tuning of risk assessment and consequent decision-making regarding remediation measures. 
Table 7

Air inhalation concentration $C_{\text {air }}$-inhalation (ppm) under the different recharge rates of the sites and different leaking times for two concentration values in the storage tank, namely mean value $(\bar{m})$ and mean plus 1 sigma dispersion $(1 \sigma)$.

\begin{tabular}{|c|c|c|c|c|c|c|c|c|c|c|c|c|c|c|c|c|c|c|c|c|c|c|c|c|}
\hline \multirow{3}{*}{$\frac{\text { Recharge rate }}{\text { Leaking days }}$} & \multicolumn{8}{|c|}{ Concentration $(\mathrm{ppm})$ at $\mathrm{V}_{\mathrm{L}}=0.01 \mathrm{~cm} / \mathrm{d}$} & \multicolumn{8}{|c|}{ Concentration $(\mathrm{ppm})$ at $\mathrm{V}_{\mathrm{L}}=0.1 \mathrm{~cm} / \mathrm{d}$} & \multicolumn{8}{|c|}{ Concentration $(\mathrm{ppm})$ at $\mathrm{V}_{\mathrm{L}}=1 \mathrm{~cm} / \mathrm{d}$} \\
\hline & \multicolumn{2}{|c|}{10} & \multicolumn{2}{|l|}{100} & \multicolumn{2}{|l|}{1000} & \multicolumn{2}{|l|}{10,000} & \multicolumn{2}{|l|}{10} & \multicolumn{2}{|l|}{100} & \multicolumn{2}{|l|}{1000} & \multicolumn{2}{|c|}{10,000} & \multicolumn{2}{|l|}{10} & \multicolumn{2}{|l|}{100} & \multicolumn{2}{|l|}{1000} & \multicolumn{2}{|l|}{10,000} \\
\hline & $\bar{m}$ & $1 \sigma$ & $\bar{m}$ & $1 \sigma$ & $\bar{m}$ & $1 \sigma$ & $\bar{m}$ & $1 \sigma$ & $\bar{m}$ & $1 \sigma$ & $\bar{m}$ & $1 \sigma$ & $\bar{m}$ & $1 \sigma$ & $\bar{m}$ & $1 \sigma$ & $\bar{m}$ & $1 \sigma$ & $\bar{m}$ & $1 \sigma$ & $\bar{m}$ & $1 \sigma$ & $\bar{m}$ & $1 \sigma$ \\
\hline Acetophe & 0 & 0 & 0 & 0.00 & 0.0016 & 0.00 & 0.0016 & 0.00 & 0 & 0 & 0 & 0.00 & 0 & 0.00 & 0 & 0.00 & 0.0075 & 0.01 & 0 & 0.00 & 0 & 0.00 & 0 & 0.00 \\
\hline Benzene & 0 & 0 & 20.02 & 27.23 & 56.22 & 76.46 & 73.57 & 100.06 & 0 & 0 & 19.45 & 26.45 & 54.47 & 74.08 & 70.78 & 96.26 & 0.25 & 0.00 & 14.58 & 19.83 & 35.88 & 48.80 & 39.29 & 53.43 \\
\hline Phenol & 0 & 0 & 0 & 0.00 & 0 & 0.00 & 0 & 0.00 & 0 & 0 & 0 & 0.00 & 0 & 0.00 & 0 & 0.00 & 0 & 0.00 & 0 & 0.00 & 0 & 0.00 & 0 & 0.00 \\
\hline TEX & 0 & 0 & 9.23 & 12.55 & 57.75 & 78.54 & 92.16 & 125.34 & 0 & 0 & 9.0057 & 12.25 & 55.91 & 76.04 & 88.84 & 120.82 & 0.33 & 0.45 & 6.99 & 9.51 & 37.79 & 51.39 & 50.14 & 68.19 \\
\hline TMB & 0 & 0 & 0.21 & 0.29 & 2.93 & 3.98 & 5.94 & 8.08 & 0 & 0 & 0.21 & 0.29 & 2.83 & 3.85 & 5.69 & 7.74 & 0.023 & 0.03 & 0.16 & 0.22 & 1.86 & 2.53 & 3.03 & 4.12 \\
\hline R-Benzene & 0 & 0 & 0.52 & 0.71 & 23.08 & 31.39 & 68.52 & 93.19 & 0 & 0 & 0.52 & 0.71 & 22.72 & 30.90 & 67 & 91.12 & 0.32 & 0.44 & 0.46 & 0.63 & 18.66 & 25.38 & 51.06 & 69.44 \\
\hline NAPH & 0 & 0 & 0 & 0.00 & 0.00045 & 0.00 & 0.033 & 0.04 & 0 & 0 & 0 & 0.00 & 0 & 0.00 & 0 & 0.00 & $5.4 \mathrm{E}-4$ & 0.00 & 0 & 0.00 & 5.4E-6 & 0.00 & $1.8 \mathrm{E}-5$ & 0.00 \\
\hline PAHs-NAPH & 0 & 0 & 0 & 0 & 0 & 0 & 0 & 0 & 0 & 0 & 0 & 0 & 0 & 0 & 0 & 0 & 0 & 0 & 0 & 0 & 0 & 0 & 0 & 0 \\
\hline
\end{tabular}

Table 8

Soil concentration $\mathrm{C}_{\mathrm{S}}(\mathrm{ppm})$ on surface soil for two concentration values in the storage tank, namely mean value $(\overline{\mathrm{m}})$ and mean plus 1 sigma dispersion $(1 \sigma)$.

\begin{tabular}{|c|c|c|c|c|c|c|c|c|c|c|c|c|c|c|c|c|c|c|c|c|c|c|c|c|}
\hline \multirow{3}{*}{$\frac{\text { Recharge rate }}{\text { Leaking days }}$} & \multicolumn{8}{|c|}{ Concentration $(\mathrm{ppm})$ at $\mathrm{V}_{\mathrm{L}}=0.01 \mathrm{~cm} / \mathrm{d}$} & \multicolumn{8}{|c|}{ Concentration $(\mathrm{ppm})$ at $\mathrm{V}_{\mathrm{L}}=0.1 \mathrm{~cm} / \mathrm{d}$} & \multicolumn{8}{|c|}{ Concentration $(\mathrm{ppm})$ at $\mathrm{V}_{\mathrm{L}}=1 \mathrm{~cm} / \mathrm{d}$} \\
\hline & \multicolumn{2}{|l|}{10} & \multicolumn{2}{|l|}{100} & \multicolumn{2}{|c|}{1000} & \multicolumn{2}{|c|}{10,000} & \multicolumn{2}{|l|}{10} & \multicolumn{2}{|l|}{100} & \multicolumn{2}{|l|}{1000} & \multicolumn{2}{|c|}{10,000} & \multicolumn{2}{|l|}{10} & \multicolumn{2}{|l|}{100} & \multicolumn{2}{|l|}{1000} & \multicolumn{2}{|l|}{10,000} \\
\hline & $\bar{m}$ & $1 \sigma$ & $\bar{m}$ & $1 \sigma$ & $\bar{m}$ & $1 \sigma$ & $\bar{m}$ & $1 \sigma$ & $\bar{m}$ & $1 \sigma$ & $\bar{m}$ & $1 \sigma$ & $\bar{m}$ & $1 \sigma$ & $\bar{m}$ & $1 \sigma$ & $\bar{m}$ & $1 \sigma$ & $\bar{m}$ & $1 \sigma$ & $\bar{m}$ & $1 \sigma$ & $\bar{m}$ & $1 \sigma$ \\
\hline Acetophenone & 0 & 0 & 0 & 0 & 0 & 0 & 0 & 0 & 0 & 0 & 0 & 0 & 0 & 0 & 0 & 0 & 0 & 0 & 0 & 0 & 0 & 0 & 0 & 0 \\
\hline Benzene & 3.4 & 6.32 & 4.2 & 7.85 & 0.28 & 0.53 & 0.014 & 0.027 & 3.3 & 6.22 & 4.1 & 7.61 & 0.27 & 0.51 & 0.012 & 0.023 & 2.8 & 5.16 & 2.9 & 5.38 & 0.12 & 0.22 & 0 & 0.0001 \\
\hline Phenol & 0 & 0 & 0 & 0 & 0 & 0 & 0 & 0 & 0 & 0 & 0 & 0 & 0 & 0 & 0 & 0 & 0 & 0 & 0 & 0 & 0 & 0 & 0 & 0 \\
\hline TEX & 0.57 & 1.17 & 11.54 & 22.74 & 2.03 & 4.19 & 0.082 & 0.17 & 0.56 & 1.14 & 11.22 & 23.09 & 1.96 & 4.03 & 0.077 & 0.16 & 0.47 & 0.96 & 8.41 & 17.28 & 1.1 & 2.26 & 0.006 & 0.012 \\
\hline TMB & 0.001 & 0.0017 & 0.64 & 1.02 & 0.58 & 0.45 & 0.014 & 0.022 & 0.001 & 0.0017 & 0.62 & 0.99 & 0.27 & 0.43 & 0.013 & 0.021 & 0.0009 & 0.0014 & 0.47 & 0.75 & 0.15 & 0.24 & 0.0018 & 0.0029 \\
\hline R-Benzene & 0 & 0 & 4.49 & 8.73 & 6.73 & 13.1 & 0.48 & 0.94 & 0 & 0 & 4.44 & 8.62 & 6.58 & 12.8 & 0.47 & 0.914 & 0 & 0 & 3.9 & 7.57 & 5.2 & 10.1 & 0.29 & 0.57 \\
\hline NAPH & 0 & 0 & 0 & 0 & 0 & 0 & 0 & 0 & 0 & 0 & 0 & 0 & 0 & 0 & 0 & 0 & 0 & 0 & 0 & 0 & 0 & 0 & 0 & 0 \\
\hline PAHs-NAPH & 0 & 0 & 0 & 0 & 0 & 0 & 0 & 0 & 0 & 0 & 0 & 0 & 0 & 0 & 0 & 0 & 0 & 0 & 0 & 0 & 0 & 0 & 0 & 0 \\
\hline
\end{tabular}




\section{Acknowledgments}

This study was partially funded by the Ministerio de Economía y Competitividad, Spain [CTM2014-59828-R project]. We thank Fernando Recreo from CIEMAT for assistance and valuable contributions to the development of the ideas presented in this work.

\section{Appendix A. Supplementary data}

Supplementary data to this article can be found online at https://doi. org/10.1016/j.scitotenv.2019.133911.

\section{References}

Abualfaraj, N., Gurian, P.L., Olson, M.S., 2018. Assessing residential exposure risk from spills of flowback water from Marcellus shale hydraulic fracturing activity. Int. J. Environ. Res. Public Health 15 (4), 727. https://doi.org/10.3390/ijerph15040727 2018.

Akob, D.M., Cozzarelli, I.M., Dunlap, D.S., Rowan, E.L., Lorah, M.M., 2015. Organic and inorganic composition and microbiology of produced waters from Pennsylvania shale gas wells. Appl. Geochem. 60, 116-125. https://doi.org/10.1016/j.apgeochem.2015.04.011.

Balashov, V.N., Engelder, T., Gu, X., Fantle, M.S., Brantley, S.L., 2015. A model describing flowback chemistry changes with time after Marcellus Shale hydraulic fracturing. AAPG Bull. 99 (1), 143-154. https://doi.org/10.1306/06041413119.

Bunch, A.G., Perry, C.S., Abraham, L., Wikoff, D.S., Tachovsky, J.A., Hixon, J.G., Urban, J.D. Harris, M.A., Haws, L.C., 2014. Evaluation of impact of shale gas operations in the Barnett Shale region on volatile organic compounds in air and potential human health risks. Sci. Total Environ. 468-469 (2014), 832-842.

Clancy, S.A., Worrall, F., Davies, R.J., Gluyas, J.G., 2018. The potential for spills and leaks of contaminated liquids from shale gas developments. Sci. Total Environ. 626 1463-1473 1 June 2018

Council of Canadian Academies, 2014. Environmental Impacts of Shale Gas Extraction in Canada: Report From The Expert Panel of Harnessing Science and Technology to Understand the Environmental Impacts of Shale Gas Extraction. Retrieved from. http:// www.scienceadvice.ca/uploads/eng/assessments\%20and\%20publications\%20and\% 20news\%20releases/shale\%20gas/shalegas_fullreporten.pdf.

DiGiulio, D.C., Wilkin, R.T., Miller, C., Oberley, G., 2011. Investigation of Ground Water Contamination near Pavillion, Wyoming (Draft). Office of Research and Development, National Risk Management Research Laboratory.

Drollette, B.D., Hoelzer, K., Warner, N.R., Darrah, T.H., Karatum, O., O'Connor, M.P., Nelson, R.K., Fernandez, L.A., Reddy, C.M., Vengosh, A., Jackson, R.B., Elsner, M., Plata, D.L. 2015. Elevated levels of diesel range organic compounds in groundwater near Marcellus gas operations are derived from surface activities. Proc. Natl. Acad. Sci. 112 (43), 13184-13189. https://doi.org/10.1073/pnas.1511474112.

Elliott, E.G., Ettinger, A.S., Leaderer, B.P., Bracken, M.B., Deziel, N.C., 2016. A systematic evaluation of chemicals in hydraulic-fracturing fluids and wastewater for reproductive and developmental toxicity. J. Expo. Sci. Environ. Epidemiol. May 2015, 1-10. https://doi.org/10.1038/jes.2015.81.

Ethridge, S., Bredfeldt, T., Sheedy, K., Shirley, S., Lopez, G., Honeycutt, M., 2015. The Barnett Shale: from problem formulation to risk management. J. Unconv. Oil Gas Resour. 11 (2015), 95-110.

Gross, S.A., Avens, H.J., Banducci, A.M., Sahmel, J., Panko, J.M., Tvermoes, B.E., 2013. Analysis of BTEX groundwater concentrations from surface spills associated with hydraulic fracturing operations. J. Air Waste Manage. Assoc. 63 (4), 424-432. https://doi.org/ 10.1080/10962247.2012.759166.

Hayes, T., 2009. Sampling and Analysis of Water Streams Associated With the Development of Marcellus Shale Gas.

He, Y., Flynn, S.L., Folkerts, E.J., Zhang, Y., Ruan, D., Alessi, D.S., Martin, J.W., Goss, G.G., 2017. Chemical and toxicological characterizations of hydraulic fracturing flowback and produced water. Water Res. 114 (2017), 78-87.

He, Y., Sun, C., Zhang, Y., Folkerts, E.J., Martin, J.W., Goss, G.G., 2018. Developmental toxicity of the organic fraction from hydraulic fracturing flowback and produced waters to early life stages of zebrafish (Danio rerio). Environ. Sci. Technol. 52 (6), 3820-3830. https://doi.org/10.1021/acs.est.7b06557 2018 Mar 20. (Epub 2018 Feb 8).

IEA, 2017. World Energy Outlook 2017. IEA Publications (ISBN Print: 978-92-64-28205-6/ PDF: 978-92-64-28230-8)
ITRC (Interstate Technology \& Regulatory Council), 2015. Integrated DNAPL Site Characterization and Tools Selection (ISC-1). Interstate Technology \& Regulatory Council, DNAPL Site Characterization Team, Washington, DC www.itrcweb.org/DNAPL-ISC tools-selection. Appendix I. Representative Values for $\mathrm{F}_{\mathrm{oc}}$. http://www.itrcweb.org/ DNAPL-ISC tools-selection/Content/Appendix\%20I.\%20Foc\%20Tables.htm Publication Date: April 2015.

Jury, W.A., Spencer, W.F., Farmer, W.J., 1983. Behavior assessment model for trace organics in soil - I: model description. J. Environ. Qual. 12 (4), 558-564. https://doi. org/10.2134/jeq1983.00472425001200040025x v.

Jury, W.A., Russo, D., Streile, G., Abd, H.E.L., 1990. Evaluation of volatilization by organic chemicals residing below the soil surface. 26 (1), 13-20.

Kondash, A., Vengosh, A., 2015. Water footprint of hydraulic fracturing. Environ. Sci. Technol. Lett. 2 (10), 276-280 2015.

Kondash, A.J., Lauer, N.E., Vengosh, A., 2018. The intensification of the water footprint of hydraulic fracturing. Sci. Adv. 4 (8), eaar5982. https://doi.org/10.1126/sciadv. aar5982.

Krupnick, A., Gordon, H., Olmstead, S., 2013. Pathways to Dialogue: What the Experts Say About the Environmental Risks of Shale Gas Development: No. February. p. 78.

Kuwayama, Y., Roeshot, S., Krupnick, A., Richardson, N., Mares, J., 2015. Pits Versus Tanks : Options for On-site From Shale Gas: Resources for the Future. Discussion Paper RFF DP. pp. 15-53 (December 2015).

Lauer, N.E., Harkness, J.S., Vengosh, A., 2016. Brine spills associated with unconventional oil development in North Dakota. Environ. Sci. Technol. 2016 (50), 5389-5397.

Luek, J.L., Gonsior, M., 2017. Organic compounds in hydraulic fracturing fluids and wastewaters: a review. Water Res. 123 (2017), 536-548.

Ma, Lanting, 2018. Environmental Risks Associated with Flowback and Produced Waters in Shale Gas Projects. PhD thesis. E.T.S.I. de Minas y Energía (UPM) https://doi.org/ 10.20868/UPM.thesis.51678.

Ma, L., Hurtado, A., Eguilior, S., Llamas, J.F., 2018. A model for predicting organic compounds concentration change in water associated with horizontal hydraulic fracturing. Sci. Total Environ. 625 (2018), 1164-1174.

McKenzie, L.M., Witter, R.Z., Newman, L.S., Adgate, J.L., 2012. Human health risk assessment of air emissions from development of unconventional natural gas resources. Sci. Total Environ. 424 (2012), 79-87.

NCBI - National Center for Biotechnology Information, 2017. PubChem Compound Database; $\mathrm{CID}=996$. https://pubchem.ncbi.nlm.nih.gov/compound/996, Accessed date: 24 April 2017.

Patterson, L.A., Konschnik, K.E., Wiseman, H., Fargione, J., Maloney, K.O., Kiesecker, J., Nicot, J.-P., Baruch-Mordo, S., Entrekin, S., Trainor, A., Saiers, J.E., 2017. Unconventional oil and gas spills: risks, mitigation priorities, and state reporting requirements. Environ. Sci. Technol. 51, 2563-2573 2017.

Ravi, V., Johnson, J.A., 1997. VLEACH A One-dimensional Finite Difference Vadose Zone Leaching Model. United States Environmental Protection Agency Office of Research and Development.

Rivett, M.O., Wealthall, G.P., Dearden, R.A., McAlary, T.A., 2011. Review of unsaturatedzone transport and attenuation of volatile organic compound (VOC) plumes leached from shallow source zones. J. Contam. Hydrol. 123 (3-4), 130-156 25 April 2011.

Shan, C., Stephens, D.B., 1995. An analytical solution for vertical transport of volatile chemicals in the vadose zone. J. Contam. Hydrol. 18 (4), 259-277. https://doi.org/ 10.1016/0169-7722(95)00011-J.

Troldborg, M., Binning, P.J., Nielsen, S., Kjeldsen, P., Christensen, A.G., 2009. Unsaturated zone leaching models for assessing risk to groundwater of contaminated sites. J. Contam. Hydrol. 105 (2009), 28-37.

U.S. EPA, 2015. Assessment of the Potential Impacts of Hydraulic Fracturing for Oil and Gas on Drinking Water Resources (External Review Draft). U.S. Environmental Protection Agency, Washington, DC (EPA/600/R-15/047, 2015).

Veiguela, M. Hurtado, A, Eguilior, S., Recreo, F., Roqueñi, N., Loredo, J. 2016. A risk assessment tool applied to the study of shale gas resources. Sci. Total Environ. 571 (2016), 551-560.

Vengosh, A., Jackson, R.B., Warner, N., Darrah, T.H., Kondash, A., 2014a. Risks to water resources from shale gas development and hydraulic fracturing in the United States. Environ. Sci. Technol. 16 (4), 6838. https://doi.org/10.1021/es405118y.

Vengosh, A., Jackson, R.B., Warner, N., Darrah, T.H., Kondash, A., 2014b. A critical review of the risks to water resources from unconventional shale gas development and hydraulic fracturing in the United States. Environ. Sci. Technol. 48, 8334-8348 2014

Werner, A.K., Vink, S., Watt, K., Jagals, P., 2015. Environmental health impacts of unconventional natural gas development: a review of the current strength of evidence. Sci. Total Environ. 505 (2015), 1127-1141. 